\title{
Beobachtungen und Erfahrungen über Ruhr in Ostasien.
}

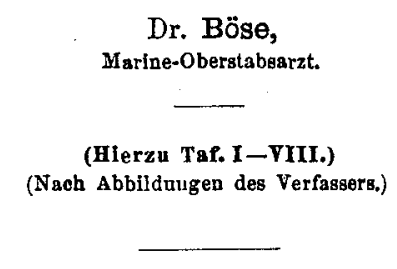

Die nachfolgenden Mitteilungen beziehen sich groBenteils auf eigene Beobachtungen und Erfahrungen während einer fast 4 jährigen Tätigkeit an der ostasiatischen Küste. Und zwar handelt es sich hier rorwiegend um das deutsche Schutzgebiet; doch muß auch dem übrigen östlichen Asien, also China, Japan, dem insulären und festländischen Ostindien naturgemäß einige Aufmerksamkeit geschenkt werden.

Die gegenwärtig ziemlich allgemein anerkannte ätiologische Einteilung in Bazillen- und Amöbenruhr erlaubt eine einigermaBen klare Übersicht. Beim Zurückgreifen auf die Forschungen früherer Jahrzehnte aber muB diese Unterscheidung vielfach fallen, wie auch vorläufig noch in klinischer, therapeutischer und prophylaktischer Hinsicht beide Ruhrarten in der Hauptsache gemeinsam besprochen werden können.

\section{Infektionsbedingungen.}

Die Kranken bezeichnen als Veranlassung zu ihrem Leiden nach dem, was in den Krankenblättern des Gouvernementslazaretts Tsingtau aus den Jahren 1898 bis $1903^{1}$ verzeichnet ist, in etwa $1 / 3$ aller Fälle eine Erkältung (unter 466 Fällen des erwähnten Zeitraumes 133 mal). In der Folgezeit wurde dies indessen viel öfter angegeben, für das Jahr 1905/06 sogar in der Mehrzahl der Fälle.

\footnotetext{
1 Hier sind die in den Sanitätsberichten der Marine nicht erwähnten, im Gouvernementslazarett behandelten Zivilpersonen mitgerechnet. Zeitschr. $f$. Hggiene. LXI.
} 
Ähnlich äußern sich die Verfasser der Sanitätsberichte der ostasiatischen Expeditionstruppen und andere.

Besonders die Neuangekommenen, noch Unerfahrenen sind sehr geneigt, schon beim Beginn der heißen Jahreszeit ihre Kleidung zu leicht zu wählen. Das ungenügende Warmhalten des Unterleibes, besonders in den Abendstunden, rächt sich aber oft. Die Temperaturunterschiede zwischen Tag und Nacht sind jedenfalls im nördlichen Ostasien im Sommer oft recht erhebliche.

In den Sanitätsberichten der Kriegsschiffe finden sich unter anderen zwei deutliche Beispiele für eine gewisse ursächliche Beziehung der Erkältung zur Rubrerkrankung.

Als die "Gazelle" 1864 von Singapore aus die Heimreise angetreten hatte; sank im Indischen Ozean die Temperatur plötzlich von 23 auf $8^{\circ} \mathrm{C}$, schlechtes Wetter führte zu häufigen Durchnässungen und Erkältungen, und kurz darauf setzte eine schwere Darmkatarrh- und Ruhrepidemie ein.

Sobald das Wetter wieder milder wurde, sank die Morbidität, um später in nördlichen Gewässern von neuem aufzuflackern.

Ähnliches wird von der "Vineta" berichtet. Im Jahre 1880 fiel auf der Reede von Tschifu die Temperatur in 12 Stunden von 25 auf $12^{\circ} \mathrm{C}$. 2 Tage später brach die Ruhr aus.

Auch von anderer Seite werden über die Einwirkung von Erkältungen bei Ruhr vielfach Mitteilungen gemacht (Virchow, Dutroulau, Hirsch, Kelsch und Kiener, Dudgeon, Herhold u. a.).

Weiterhin wird die Widerstandskraft dẹ Körpers abgeschwächt durch übergroBe körperliche Anstrengungen (Virchow, Herz u. a.).

Hin Beispiel hierfür ist die schwere Epidemie, welche 1862 auf der „Arcona" kurz nach dem Verlassen von Bangkok ausbrach. Hier erkrankten besonders die Bootsgäste, welche öfter durch ihre schwere Arbeit in der Tropenhitze erschöpft waren, während die an Land untergebrachten Seesoldaten, die doch zweifellos einer Infektion in hohem $\mathrm{MaBe}$ ausgesetzt waren, nur zu einem geringen Teil befallen wurden.

$\mathrm{DaB}$ GenuB schlecht gereinigten Obstes und ungekochter Feldfrüchte, z. B. Salat und Radieschen, die Ruhransteckung vermitteln kann, ist wohl anzunehmen, und die Sitte der Chinesen, ihre Felder mit Menschenkot zu düngen, ist bekannt.

Bezüglich des Trinkwassers gehen die Ansichten der Autoren hinsichtlich der Bazillenruhr noch auseinander. Dennoch kommt dasselbe auch bei letzterer gelegentlich als Träger der Ruhrkeime in Frage (Döberitzer Epidemie, ferner eine von Dörr beschriebene in Österreich).

Korentschewski züchtete in der Mandschurei während des russischjapanischen Krieges aus dem Wasser eines verdächtigen Brunnens Ruhr- 
bazillen, die von künstlichem hochwertigen Serum (1:700) agglutiniert wurden. Nach Schließung des Brunnens hörten die Rubrerkrankungen im benachbarten Lager auf. Auch während der chinesischen Wirren sollen sich viele Soldaten durch Trinken schmutzigen FluBwassers eine Ruhrinfektion zugezogen haberi.

Hinsichtlich der Amöbeninfektion wird das Wasser mebr allgemein: als verdächtig angesehen (Ruge, Janowski u. a.), wenngleich sich auch gegen diese Annahme Stimmen erhoben haben (de Haan und Kiewit de Jonge). Erwähnt seien ferner die Untersuchungsergebnisse ron. Musgrave und Klegg, welche mit Hilfe von aus Wasser erhaltenen: Amöben klinisch und pathologisch-anatomisch dysenterische Erscheinungen erzeugt zu haben angeben.

Selterswasser und süße Limonaden müssen ebenfalls als verdächtig angesehen werden (Quincke \& Roos, Pfuhl, Sanitätsberichte der Marine, Sanitätsbericht der Ostasiatisehen Besatzungsbrigade).

DaB auch Staub und Fliegen eine gelegentliche Ruhrinfektion vermitteln können, wird behauptet.

Die häufigste Verbreitungsart bleibt aber, und zwar für beide Ruhrarten, die Utbertragung durch den Menschen und seine Gebrauchsgegenstände, und hier spielen natürlich die Lebensgewohnheiten eine groBe Rolle. Bisher wurde dies nur für die bazilläre Dysenterie angenommen. Nach Dopters Mitteilung indessen, daB aus den Tropen heimgekehrte, mit Dysenterieamöben infizierte Soldaten die Krankheit auf ihre gesunden Kameraden übertrugen; ferner nach Vierecks Feststellungen, daB das Maschinen- und Heizerpersonal der Handelsschiffe mit groBer Wahrscheinlichkeit durch den vielen Verkehr mit Eingeborenen beim Kohlennehmen usw. sich oft eine Amöbenruhr zuzieht, darf auch für die Amöbendysenterie eine häufige direkte Übertragung angenommen werden.

Am wichtigsten sind bezüglich der Weiterverbreitung der Seuche wohl die Aborte. Von den oft von Schmutz starrenden Latrinen der Eingeborenen, wo Kotteile an die Kleidung und das Sehuhwerk des Benutzenden gelangen müssen, gar nicht zu reden, ist bei den im Beginn der Ruhr öfters profuseren Diarrhöen, und bei der Hast, mit der die vom Stuhldrang gequälten Kranken die Klosetts aufsuchen, nur zu leicht eine Beschmutzung der Sitzbretter möglich. Ebenso können dann Kotteilchen an die Hände des Kranken und hierdurch an Türklinken, Treppengeländer usw. gelangen, wo sie von Gesunden abgestreift werden.

Auch die Kleidung Ruhrkranker wird leicht rerunreinigt, so daB auch auf diesem Wege keimhaltige Kotteile an Stühle, Bänke, Tische kommen können, um dann an den Händen Gesunder zu haften und bei 
der Nahrungsaufnahme in den Verdauungskanal zu gelangen, wo sie sich bei einem schon vorhandenen Katarrh leicht weiter entwickeln.

\section{Krankheitsbild.}

Es ist von verschiedenen Seiten behaüptet worden, daB sich die Bazillen- von der Amöbenruhr klinisch scharf unterscheide. Das mag für viele Fälle zutreffen, bei weitem aber nicht für alle. Wenn auch häufig die Amöbenruhr mehr schleichend beginnen mag, als die bazilläre, und die Stühle bei jener nicht so zablreich sind, wie bei dieser; chronische Fälle kommen aber auch bei der Bazillenruhr vor. Ich habe Dutzende von Fällen gesehen, deren Stühle mit allen Kautelen ganz frisch nach der Entleerung und unter dauernder Warmhaltung wiederholt, zum Teil sogar sehr oft, vergeblich auf Amöben durchsucht wurden, und welche doch einen ganz ausgesprochen chronischen Verlauf zeigten.

Ein Sanitätsoffizier litt noch nach seiner Rüekkehr ans Ostasien nach Deutschland an dysenterischen Stühlen, in denen der Bacillus Flexner nachgewiesen wurde (Morgenroth).

Utber den klinischen Verlauf der von uns in Tsingtau beobachteten, meist bazillären Fälle, sei folgendes mitgeteilt. Die Besinnung blieb meistens erhalten, selbst bei schlechtem Kräftezustande und bis kurz vor dem Tode. Delirien wurden unter 757 Fällen nur einmal beobachtet. Dagegen bestand öfters, trotz gröBter Müdigkeit, Schlaflosigkeit.

Fieber fand sich in 466 Fällen der Jahre 1898 bis 1903 in leichtem Grade (bis $38^{\circ} \mathrm{C}$ ) $120 \mathrm{mal}$, in sehwererem Grade 51 mal. Sehr hohe Temperaturen, über $39^{\circ}$, ebenso Schüttelfröste kamen nur ausnahmsweise vor. Im Jahre 1903/04 bestand Fieber in etwa der Hälfte, 1904/05 in etwas über der Hälfte aller Ruhrfälle. Es sank indes bei unkomplizierter Dysenterie nach wenigen Tagen.

Beim Ostasiatischen Marine-Expeditionskorps wurde in zwei Drittel aller Fälle Fieber gefunden (San.-Ber. 1899/01).

Herhold sah bei seinen Ruhrkranken des Ostasiatischen ArmeeExpeditionskorps meist nur niedrige Fieberanstiege im Beginn der Erkrankung.

Auf dem während der Wirren in Ostasien stationierten Lazarettschiff "Gera" wurde unter 47 Ruhrfällen in den ersten Tagen öfters Fieber mit Remissionen und schlieBlichem kritischen $A b f a l l$ beobachtet, nur einmal eine Continua. Auf dem Lazarettschiff "Savoia" wurde bei 12 Ruhrfällen 8 mal Fieber von unregelmäBig remittierendem Charalter festgestellt. Hier handelte es sich wohl aber fast nur um schwerere, komplizierte Fälle (Luce und Meinecke). Die Fieberstatistik der "Gera“" wird ebenfalls nicht als eine durchschnittliche anzusehen sein. 
Beobachtungen und Erfahrungen Über Rutr in Ostasien. 5

Wenn man danach nur die im Kiautschougebiete während der Jahre 1898 bis 1905 vorgekommenen Ruhrfälle (unter Zurechnung der im dortigen Lazarett behandelten Zivilpersonen), sowie diejenigen des Marineexpeditionskorps in Betracht zieht, im ganzen 986, so ergibt sich, daB Fieber in ungefähr der Hälfte der Fälle auftrat.

EiweiB ist nur ausnahmsweise im Urin gefunden worden.

Die Zunge war meist mehr oder weniger dick belegt.

Der Leib war selten aufgetrieben, oft dagegen eingesunken, in akuten sowohl wie in chronischen Fällen, wenn nicht eine Komplikation vorhanden war.

Die Bauchdecken waren öfters, zuweilen sogar in erheblichem Grade, druckempfindlich; beim Abtasten des Dickdarmverlaufs fühlte und hōrte man häufig ein Gurren, besonders an den seitlichen Teilen.

Uber Schmerzen wurde in jenen 466 Fällen der Jahre 1898 bis 1903 (nach den Krankenblattaufzeichnungen) geklagt:

im ganzen Leibe . . . . . . . . . . . . . . 54 mal. in der Gegend des Blinddarms . . . . . . . . . . . 16 "

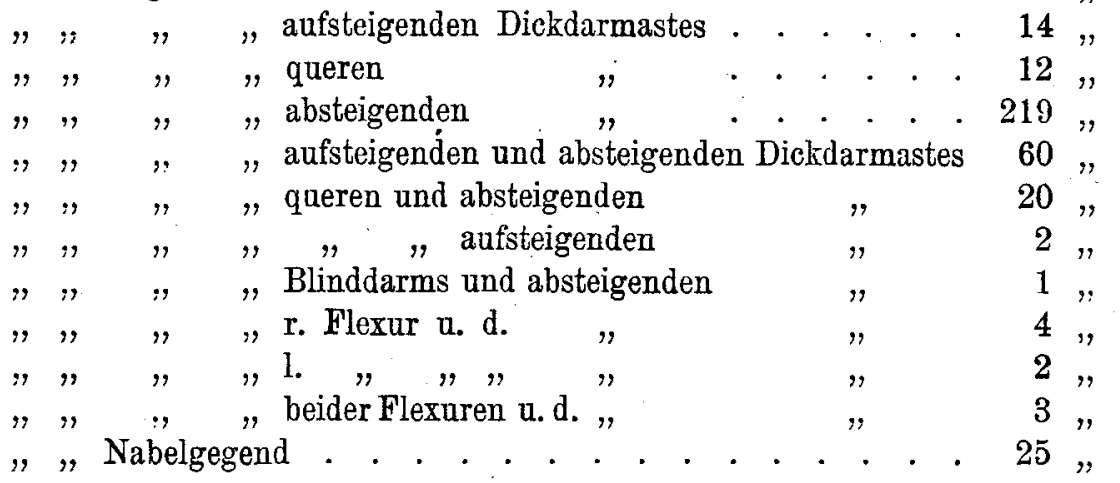

Weitaus am häufigsten ist also der absteigende Dickdarmast, teils allein, teils mit anderen Darmpartien zusammen befallen. Auch war er in der Tiefe vielfach als ein gummischlauchartiges, in akuten Fällen fast stets druckempfindliches Gebilde zu fühlen.

Die Stühle boten im Vergleich zu den sonst bei Ruhr beobachteten keine Unterschiede.

GröBere, gefahrdrohende Blutrerluste durch die Stühle wurden in Tsingtau nur selten beobachtet. Haasler sah in Nordehina mehrere Fälle von schwerer Darmblutung, von denen zwei mit dem Tode endeten. Beide waren mit I eberabszeB kompliziert.

Strong erwähnt vier Fälle von tödlicher Blutung bei Amöbendysenterie, die alle durch LeberabszeB kompliziert waren. Er ist wie 
Haasler der Ansicht, daB die Lebererkrankung eine Disposition zu Darmblutungen schaffe. Während aber $\mathrm{Ha}$ asler an eine hämorrhagische Diathese denkt, erwähnt Strong die Erklärung Finlaysens, der die starke Kongestion des Dickdarmes, welche zur Blutung führt, als eine mechanische Behinderung seitens der Pfortaderzirkulation auffaBte.

DaB erhebliche Darmblutungen eigentlich seltener sind, als man bei dem oft hochgradigen Zerstörungsprozesse in der Darmwand erwarten sollte, erklärt Musgrave mit einer Entzündung der Gefäßinnenhaut und Thrombuse, die oft in der Nähe der Geschwüre beobachtet werde.

Bei Amöbenruhr habe ich in zwei Fällen gegen Ende.des Lebens dunkelrote, nur aus Blut und gangränösen Darmteilen bestehende, etwas faulig riechende Stūhle beobachtet, welche fast ununterbrochen aus dem weitgeöffneten After ansflossen.

Die mit diesen Stühlen herausgesehwemmten, als solche in Schnitten histologisch erkannten Darmwandfetzen hatten die Höchstlänge von $5^{\mathrm{cm}}$. Doch sind schon weit gröBere Stücke beobachtet worden (Councilman und Lafleur).

In der Rekonvaleszenz wurden öfter bei beiden Ruhrarten Tage, ja eine Woche lang - und diese Erkenntnis ist für die Behandlung nicht ohne Bedeutung - völlig normale Stühle entleert, bis dann eines Morgens ganz unerwartet einige EBlöffel mißfarbigen. Schleimes im Steckbecken sich vorfanden.

In subakuten und chronischen Fällen sahen wir im Stuhl oft die bekannten, froschlaichartigen oder sagoförmigen Gebilde, welche nach Virchow teils aus Schleimklümpchen, teils aus unverdauten Stärkekörnchen bestehen. Erstere entstehen in cystisch entarteten Drüsenschläuchen der Dickdarmwand (Virchow). Auf Taf. VI ist eine solche Schleimcyste von einem Falle chronischer Amöbenruhr dargestellt, in der sich ein Schleimklümpchen befindet, wie ich in genau derselben Strultur im Stuhl gefunden und später in Schnitten untersucht habe.

\section{Krankheitsdauer.}

Die Dauer der Krankheit, welche in akuten, leichten Fällen 2 bis 3 Wochen beträgt, kann, wenn diese einmal in das chronische Stadium übergegangen ist, eine ziemlich lange sein, sich auf Monate, ja Jahre erstrecken, und zwar letzteres besonders bei Amöbenruhr.

Vielfach - und diese Beobachtung konnten wir in Tsingtau hauptsächlich an der Zivilbevölkerung machen - sieht der Kranke, sobald er den akuten Beginn des Leidens überwunden hat, sich bereits als gesund an und läbt die ärztlichen Anordnungen fortan mehr oder weniger unbeachtet. 
Er kleidet sich wieder zu leicht, nimmt wieder geeiste Getränke zu sich, iBt.reichlich Obst und Salate und wundert sich dann, wenn er eines Tages plötzlich wieder Schleim und Blut im Stuhl hat und sich elend fühlt.

Viele Leute in Ostasien haben sich bereits so an die allgemeinen Klagen über Diarrhöen und Ruhranfälle zur Sommer- und Herbstzeit gewöhnt, daB sie dieselben nur im Scherz erwähnen. Sie behandeln sich selber mit den ihnen rom Apotheker empfohlenen Mitteln und Rotweinpunsch und verschleppen so ein Leiden, das ihnen Jahre ihres späteren Lebens verbittern oder dasselbe frühzeitig beenden kann.

Ich habe hier in Deutschland Patienten aus Tsingtau wiedergetroffen, welche immer noch gelegentlich unter den Folgen einer alten Ruhr zu leiden hatten. Der geringste Diätfehler, ein Glas Bier, ein nur kurzes Abkühlen ihres Unterleibes führte binnen kurzem zu Koliken und Darchfällen. Oder eine ungeeignete Kost rief schwere Verstopfung und qualvolle Auftreibung des Leibes durch Blähungen hervor.

Dieser chronische Verlauf der Krankheit kann gelegentlich zur Hypochondrie, ja zum Lebensüberdruß führen. Sonst nüchtern und objektiv denkende Leute können schließlich dahin kommen, daB sie ängstlich jede Darmentleerung mit Hilfe von Holzstückchen auf kleine Schleimfetzchen genau durchsuchen und untröstlich sind, wenn sie irgend eine Absonderlichkeit entdecken.

\section{Komplikationen.}

Von den mit beiden Ruhrarten in ursächlichem Zusammenhange stehenden Komplikationen sind schon eine ganze Reihe in der Literatur mitgeteilt worden, und zwar ist auf diesem Gebiete eine einigermaßen scharfe klinische Trennung für beide Ruhrarten möglich.

Bei Bazillenruhr werden am häufigsten, besonders zur Zeit der Rekonvaleszenz, Störungen von seiten des Herzens gefunden. Nenninger hat an Bord des Lazarettschiffes "Gera" unter 47 allerdings besonders schweren Ruhrfällen 14 derartige (29.7 Prozent) festgestellt. In einigen wurde die Herzerkrankung durch Pulsbeschleunigung, in anderen dureh eine Verbreiterung einer oder beider Herzhälften, sowie Geräusche angedeutet. Nenninger nimmt eine Toxinwirkung als Ursache der Herzerkrankung an, analog den bei anderen Infektionskrankheiten längst bekannten Herzkomplikationen. Ähnlich haben sich neuerdings Kraus und Dörr geäuBert.

Im Marinefeldlazarett zu Peking wurde unter 89 Rahrfällen viermal eine nervöse Störung der Herztätigkeit, auf dem Lazarettsehiff "Savoia“" zweimal eine Verbreiterung des Herzens nach links gefunden. 
In den Krankenblättern des Gouvernementslazaretts Tsingtau aus den Jahren 1898 bis 1902 ist 16 mal eine nerröse Störung der Herztätigkeit, zweimal ein systolisches Geräusch über dem Herzen (davon einmal mit gleichzeitigem Fieber) und einmal eine Verbreiterung der Herzgrenzen aufgezeichnet.

In den Jahren 1903 bis 1905 wurde neunmal eine nervöse Störung der Herztätigkeit und riermal eine Herzmuskelerkrankung bzw. Leistungsschwäche festgestellt. Danach ist also an 757 Kranken des Kiautschougebietes in über 4 Prozent aller Fälle eine Komplikation von seiten des Herzens beobachtet worden.

Eine Verlangsamung der Herztätigkeit, wie Dörr sie angibt, wird sonst nirgends erwähnt, ist aber von mir in einzelnen Fällen ebenfalls, und zwar vorübergehend, gefunden worden.

Wenn es sich nun auch bei den dysenterischen Herzerkrankungen vielfach um vorübergehende Störungen handelt, so sind dieselben doch sehr ernst zu nehmen. So war bei den von Nenninger beobachteten Fällen der Zustand des Herzens auch nach Ablauf der Ruhr mehrfach noch ein derart mangelhafter, daß von jenen $14 \mathrm{Mann}$, welche unter Herzkomplikationen gelitten hatten, sechs später invalidisiert werden muBten.

Komplikationen von seiten der Gelenke wurden im Kiautschougebiete unter 757 Rubrfällen nur 5 mal beobachtet; auch beim Marineexpeditionskorps und an Bord der "Gera" kamen nur wenige derartige F'alle vor.

Von Entzündung der Sehnenscheiden und Ohrspeicheldrüsen, die Shiga sah, findet sich in unseren Krankenblättern nichts verzeichnet.

Akute Bindehautentzündungen wurden in jenen 757 Fällen dreimal gefunden.

Von seiten der Atmungsorgane sind in Tsingtau nie Komplikationen beobachtet worden, abgesehen von den Fällen, wo gleichzeitig LeberabszeB bestand, dagegen werden sie von Haasler (Tientsin) erwähnt.

Eine Erkrankung des Nervensystems wird in den Tsingtauer Krankenblättern, abgesehen von den nervösen Herzstörungen, nur einmal vermerkt. Es handelte sich um einen Fall der Gefühlsherabsetzung auf der Haut eines Armes und Kriebeln in der Kopfhaut. Atrophien der Muskeln, wie in Döberitz, schwerere Erkrankungen des Nervensystems, wie sie Kelsch und Kiener, Leyden, Lenhartz and Gärtner mitteilen, haben wir in Tsingtau nie gesehen.

Herpes ist wiederholt, sowohl auf der "Gera" wie im Lazarett Tsingtau (unter 757 Fällen dreimal) gesehen worden.

Thrombosen, wie sie anderweit beobachtet wurden (Laveran, Haasler, Nenninger) sahen wir nie. 
Beobachtungen und Erfahrungen Über Ruhr in Ostasten. 9

Schmerzen in den Hoden und im Samenstrange kamen unter 757 Fällen zweimal vor.

Blasenschmerzen werden in jenen 466 Krankenblättern sechsmal erwähnt. Es hat sich hier wohl um Blasentenesmus gehandelt, der bei schweren Durchfällen vorkommt. In den letzten Jahren wurde nie darüber geklagt.

Zu einer weiteren Komplikation, der Bauchfellentzündung, kommt es bei Amöbenruhr wohl leichter als bei der bazillären. Meistens handelt es sich freilich nur um eine umschriebene Erkrankung, welche durch den tief in das Darmgewebe hineinreichenden ZerstörungsprozeB hervorgerufen wird und zu nachträglichen Verklebungen und Verwachsungen mit den Nachbarteilen führt, das Leben aber nicht unmittelbar zu bedrohen braucht.

Musgrave fand in Manila bei Amöbenruhr in 80 Prozent aller Autopsien örtliche chronische Peritonitis.

Gelegentlich kann jedoch, teils ohne, teils - und zwar vorwiegend mit Durchbruch der Darmwand eine ausgedehnte akute Bauchfellentzündung entstehen.

Unter 100 Obduktionen bei Amöbenruhr fand Musgrave $26 \mathrm{mal}$ allgemeine akute Peritonitis, welche $21 \mathrm{mal}$ durch Darmperforation entstanden war, nur einmal ohne dieselbe (die übrigen vier durch LeberabszeB).

Darmperforationen sind bei Marineangehörigen in China seit 1898 bei 37 Autopsien $18 \mathrm{mal}$ beobachtet worden.

Auch Haasler sah sie im Norden mehrfach.

Die am meisten bekannte und erforschte Ruhrkomplikation sind die Lebererkrankungen, besonders die Abszesse. Während eine einfache, mit remittierendem Fieber verbundene Leberschwellung auch bei der Bazillenruhr häufiger vorkommt, wird der LeberabszeB im allgemeinen doch mehr als eine Komplikation der Amöbenruhr angesehen. Dies ist durch viele Untersuchungen, besonders die von Kartulis, Rogers und Musgrave so sicher bewiesen worden, daß man schon aus dem verhältnismäBig seltenen Auftreten von Leberabszessen in einer Ruhrgegend auf das herrschen der bazillären Form schlieBen kann.

In Tsingtau kam unter $\mathbf{7 5 7}$ Ruhrfällen 14 mal einfache Leberentzündung und $6 \mathrm{mal} \mathrm{AbszeB}$ vor. AuBerdem wurde noch in einem Pockenfalle, wo sich später auch Ruhr zeigte (wohl kaum aus Tsingtau stammend), ferner in einem anderen Falle, wo Ruhr in der Anamnese erwähnt wurde, ein offenbar alter AbszeB (vielleicht aus Westindien stammend) in der Leber gefunden. Danach ist also, selbst wenn man diese beiden Befunde noch hinzurechnet, in 757 Rubrfällen nur 8 mal LeberabszeB festgestellt worden (auBerdem kam noch ein Fall von ausgebildetem Abszeb aus der Südsee zugereist). 
Schon daraus kann man schließen, daB in Tsingtau die Amöbenruhr nicht die vorherrschende Form sein kann, da sonst der Prozentsatz wahrscheinlich ein höherer sein würde.

Unter jenen acht Tsingtauer Fällen wurden einmal multiple Abszesse festgestellt; Haasler sah dieselben in Tientsin unter vier obduzierten Fällen zweimal.

Unter multiplen Abszessen können jedoch nur solche verstanden werden, die tatsächlich in groBer Zahl vorhanden sind und den gröBten Teil der Leber durchsetzen, während die kleineren Abszesse, welche in der Nähe eines oder mehrerer groBen gefunden werden, meines Erachtens nicht als solche zu bezeichnen sind.

Die multiplen Abszesse sollen im allgemeinen sehr schnell wachsen, während die solitären oft jahrelang bestehen können (s. u.).

Von Abszeßdurchbrüchen wurden in Tsingtau zwei beobachtet, in die Brusthöhle und in den Magen (Südseefall).

Die einfache Leberentzündung der Bazillenruhr kann wohl auch zum AbszeB führen, scheint sich aber unter geeigneter Behandlung meist zurückzubilden.

Milzabszesse (Haasler) wurden in Tsingtau nicht beobachtet, ebensowenig Hirnabszesse, dagegen in einem Falle von LeberabszeB auch ein solcher in der Lunge von etwa TaubeneigröBe.

In letzter Zeit ist man mehr auf die Beteiligung des Blinddarms an der allgemeinen Darmverschwärung, besonders bei der Amöbenruhr, aufmerksam geworden (Haasler, Hoppe-Seyler). Vielleicht hängt auch das verbältnismäBig häufige Vorkommen von Blinddarmentzündung an der ostasiatischen Küste damit zusammen.

Eine öfter beobachtete Begleitkrankheit der Ruhr ist der Typhus, welcher in den Jahren 1898 bis 1903 in Tsingtau in 20 Fällen, später nicht mehr beobachtet wurde. Und zwar scheint es sich in der Mehrzahl derselben um ein Hinzutreten der Ruhr zum Typhus gehandelt zu haben, während im Marine-Feldlazarett zu Peking und auf der "Gera" das umgekehrte Verhältnis beider Krankheiten zueinander ungefähr ebenso häufig festgestellt wurde. Die Diagnose kann beim Fehlen von Roseolen im Beginn zuweilen nicht leicht sein, doch wird die Fieberkurve meist auf den richtigen Weg führen.

In den Tropen wird auch häufig Malaria mit Dysenterie vergesellschaftet vorgefunden, so oft, daß einzelne Forscher, z. B. Craig, dazu neigen, von einer Malariaruhr zu sprechen. Die von Ruge erwähnten Untersuchungen Marchiafavas und van Eeckes stellten auch gelegentlich eine starke Ansammlung von Malariaparasiten in den Darmkapillaren fest. 


\section{Nachkrankheiten.}

Von Nachkrankheiten eines schweren Ruhranfalls ist zunächst allgemeine nerröse Abspannung, dann auch Blutarmut zu erwähnen. Mir ist hier in Deutschland schon vor Jahren das graugelbe Aussehen aufgefallen, welches die aus dem damals noch von sehr sehwerer Ruhr heingesuchten Kiautschougebiete heimgeschickten Seesoldaten hatten.

Ferner besteht ofters noch lange Zeit eine Neigung zu Durchfällen, die bei scheinbar geringfügigen Diätfehlern und Erkältungen, auftreten and häufig mit Verstopfung wechseln können.

Ich habe in Tsingtau einmal kurz vor dem Abgang eines terminmäBigen Ablösungstransportes 59 demselben angehörige Mannschaften untersucht, welche innerhalb der letzten 2 Jahre an Ruhr gelitten hatten: Bei 23 derselben, also über einem Drittel, ließ sich der absteigende Dickdarmast als ein derber, in sämtlichen Fällen angeblich druckempfindlicher Wulst in der Tiefe des Leibes fühlen. $\mathrm{DaB}$ ein so veränderter, zum Teil wohl ziemlich starrer, vielleicht auch verengter Darm nicht immer regelrecht funktionieren kann, ist nicht $\mathrm{zu}$ verwundern. $16 \mathrm{der}$ Untersuchten klagten auch über gelegentliche Leibschmerzen und unregelmäBigen Stuhlgang.

Bedenkt man, daB alle Leute mit erheblichen Störungen von seiten der Ruhr schon früher heimgesandt waren, so erscheinen jene Zahlen doch ziemlich hoch.

Auch die peritonitischen Verwachsungen können noch lange nach Ausheilung der eigentlichen Ruhr Unterleibsbeschwerden hervorrufen, zumal, wenn Knickungen des Darms entstanden sind oder ausgesprochene Strangulierungen. Musgrave beschreibt eine Sanduhrformation des Blinddarms.

Ich entsinne mich eines Falles - es handelte sich um einen früher rubrkranken Kaufmann -, wo an der rechten Dickdarmbiegung ein etwa apfelgroßer, ziemlich harter, etwas versehieblicher Tumor fühlbar war. Der den sehr herabgekommenen Patienten behandelnde Zivilarzt dachte an eine operable Neubildung, die, da Verstopfung bestand, ein Hindernis für die Kotentleerung sein konnte. Bei Eröffnung der Bauchhöhle aber zeigte sich, daB die Geschwulst aus eingedicktem Kot bestand, welcher dort stecken geblieben war, sich aber weiter streichen lieB.

Ich habe ferner hier in Deutschland einen Offizier behandelt, weleher noch 4 Jahre nach einer Ruhrerkrankung, wohl infolge von Adhäsionen, zeitweilig an so schweren Blähungen litt, daB ihm das Tragen des Säbelkoppels zur Qual wurde. 


\section{Diagnose.}

Eine ausgesprochene Ruhr ist nicht leicht zu verkennen. Schwierigkeiten dagegen können, besonders beim Beginn einer Epidemie bzw. der jahreszeitlichen endemischen Neuerscheinung der Dysenterie, die ersten leichten Fälle machen, deren nicht rechtzeitige Erkennung unter Umständen, z. B. an Bord, von großer Tragweite sein kann.

Im allgemeinen wird in Ostasien von uns Marineārzten die Grenze zwischen Darmkatarrh und Ruhr durch das Auftreten von Blut im Stuhl gezogen. Freilich können auch bei heftigen Darmkatarrhen blutiggestreifte Stühle vorkommen; hier verschwindet aber das Blut sehr bald wieder, und meist auch der Schleim, während beides bei frischer Ruhr eine Zeit lang vorhanden zu sein pflegt. Andererseits gibt es auch zweifellos Rubrfälle, welche ohne Blut und nur mit Schleim einhergehen.

Prostration, Koliken, Tenesmen bilden keine Unterschiedsmerkmale.

Aus rein praktischen Gründen, sowohl rücksichtlich des Kranken, wie der Umgebung, wird man in der Regel gut tun, die Grenze für die Diagnose „Ruhr" eher etwas zu weit als zu eng zu stecken.

Unter Krankenhausbehandlung wird bei Amöbenruhr das Mikroskop, bei bazillärer vielleicht die bakteriologische Untersuchung Klarheit schaffen.

Eine exakte Differentialdiagnose zwischen Bazillen- und Amöbenruhr ist insofern von Wichtigkeit, als man bei der letzteren auch nach scheinbarem Überstehen der Krankheit wegen der Komplikationen, die das Leben bedrohen können, noch längere Zeit ein besonders wachsames Auge auf den Kranken haben muB.

Da nun nach Gebrauch von Adstringentien leicht die Amöben für einige Zeit aus den Stühlen verschwinden können, würde eine recht bald nach der Aufnahme des Kranken vorgenommene mikroskopische Untersuchung zu empfehlen sein. Das ist nötiger als Ausstriche auf Platten. Sind erst Medikamente, abgesehen von Rizinus oder Karlsbader Salz, gegeben, so kann das Auffinden von Amöben Schwierigkeiten machen.

In den Tropen mag öfters eine Verwechslung der Dysenterie, besonders in chronischen Fällen, mit der Sprue vorkommen. Hierbei findet sich aber meist Rand- oder Flächenrötung der Zunge, während diese bei Ruhr in der Regel belegt ist. Die Spruestühle reagieren auch meist sauer im Gegensatz zu den, im Beginn wenigstens, alkalischen Ruhrstühlen. Auch Balantidium-, sowie Bilharziaerkrankungen, ferner bösartige Neubildungen, tuberkulōse, luetische oder (bei Frauen) gonorrhoische Darmverschwärungen können gelegentlich zu Verwechslungen AnlaB geben.

Schwierigkeiten kann die Diagnose der Rahrkomplikationen machen 
Am wichtigsten ist die möglichst frühzeitige Erkennung eines I Jeberabszesses, da nur dann an eine Heilung durch Operation gedacht werden kann.

Sachs und andere halten in dieser Beziehung die Betrachtung des Körpers und seiner Haltung für bedeutsam: Der Kranke schone die rechte, etwas vorgewölbte Brustseite bei der Atmung, versuche sie möglichst ruhig zu stellen. Das wird für ausgesprochene Fälle sehr häufig zutreffen, für den Beginn der Erkrankung jedoch weniger. Es ist auch vorgekommen, daB AbszeBträger ùmhergelaufen sind. Ein Offizier soll sogar ein Pferderennen mitgeritten sein.

Das Hauptzeichen für den Verdacht auf LeberabszeB bei Ruhr ist meines Erachtens zunächst das remittierende Fieber bei längerem Bestehen einer Ruhr und der öfters beim Sinken desselben eintretende SchweiBausbruch. Von fieberlosen Fällen wird in der Literatur nur selten berichtet.

Ferner ist beachtenswert der rechtsseitige Schulterschmerz, der nach Sachs und Cantlie besonders im Beginn der Erkrankung auftritt, bevor es zu einer eigentlichen Einschmelzung von Lebergewebe kommt, und der stets als sebr wichtiges Symptom gegolten hat (Dutroulau, Councilman und Lafleur, Musgrave, Krämer u. a.). Gōbel freilich fand ihn nur in 50 Prozent seiner Fälle, was aber vielleicht mit der bereits vorhandenen Erweichung des Herdes zusammenhing, wo der Schmerz öfter wenig oder gar nicht vorhanden sein soll.

In den letzten Jahren ist mehrfach auf die Vermehrung der Leukozytenzahl hingewiesen worden. Schlayer fand stets über 20000; Rogers macht darauf aufmerksam, $d a B$ die Leukozyten in vorgeschrittenen, bereits anämischen Fällen oft nur relativ vermehrt sein können; Mac Callum vermiBte die Erhöhung der Leukozytenzahl öfters ganz und Musgrave legt deshalb nicht viel Wert darauf, weil die Leukozytenvermehrung eine Folge der Darmulzerationen sein könne.

Kramm empfiehlt eine Lagerung des Kranken auf die linke Seite, da dann Schmerzen in dem Organ aufzutreten pflegen. Andere wieder machen auf die Vergrößerung der Leber, besonders nach oben;, sowie auf Husten und pleuritische Symptome über dem rechten Unterlappen und gelegentliche peritonitische Reibegeräusche im rechten Epigastrium aufmerksam, sowie auf Druckempfindlichkeit der Zwischenrippenräume. Auch die schmutzig-wachsartige (Sachs) oder an Perlen erinnernde (Mac Callum) Farbe der Bindehäute, sowie das erdfahle Aussehen der Haut beim Fehlen eines eigentlichen Ikterus ist nicht unwichtig.

Aber manche von diesen Symptomen können fehlen.

Ich habe in Tsingtau sechs Fälle von LeberabszeB während des Lebens gesehen. Die Haltung war entweder Rückenlage oder etwas nach rechts 
gewendet. Ikterus bestand in vier Fällen nicht, wohl aber eine fahle Blässe. In den beiden anderen handelte es sich um einen an und für sich schon gelblichen Japaner und um eine mit ausheilenden Pockendefekten übersäte Europäerin, deren Hautfarbe eine gewisse Röte hatte.

Die Bindehäute sahen stets porzellanweiB aus.

Die Zahl der weißen'Blutkörperchen wurde nur in zwei Fällen festgestellt und betrug 19000 und 20000 .

Die Leber war in mehreren Fällen nicht so vergröBert, daB es sich durch Palpation oder Perkussion feststellen lieb. Auch eine Druckempfindlichkeit des Organs lieB sich nicht immer finden, weder in den Zwischenrippenrāumen, noch beim seitlichen Zusammenpressen des Brustkorbes.

Zwei jener Fälle habe ich schon im Beginn der Erkrankung gesehen. Beide hatten ausgesprochenes Krankheitsgefühl, Schulterschmerz, Schüttelfröste und Fieber. Während der eine Kranke eine besonders druckempfindliche Gegend angeben konnte, punktiert und erfolgreich operiert wurde, hatte der andere monatelang keinerlei Schmerzen in der Lebergegend, keine nachweisbare Vergrößerung der Leber und keine Spur von. Atemnot. Erst nach etwa $21 / 2$ Monaten - er war inzwischen tagelang fieberlos und auBer Bett gerresen - klagte er über eine gewisse Druckempfindlichkeit in einem Zwischenrippenraum, wo dann auch mit Erfolg punktiert wurde. Er erlag aber trotz Entleernng des Abszesses der Erkrankung, und bei der Obduktion zeigte sich eine über mannsfaustgroBe Höhle.

DaB Leute mit groBen Abszessen umherlaufen können, zeigen folgende ebenfalls in Tsingtau beobachtete Fälle.

Ein Bauaufseher starb nach ganz kurzem Krankenlager an der Cholera. Bei der Obduktion fand sich eine große AbszeBhöhle in der Leber. Er hatte also trotz dieses schweren Leidens seinen anstrengenden Dienst bis zum Ausbruch der tödlichen Choleraerkrankung versehen. Der Abszeß rührte vielleicht von einem früheren Aufenthalt in Westindien her.

Die schon erwähnte Frau, welche an Pocken litt, war bis kurz vor dem Beginn dieser Erkrankung angeblich gesund gewesen. Sie war früher in Ägypten, dann in Bombay, dann als Prostituierte in Shanghai wohnhaft. In der dritten Krankheitswoche fand sich Blut und Schleim in den Stühlen, das bereits gesunkene Fieber stieg von neuem, und in der Lebergegend traten Schmerzen auf. Die Probepunktion war positiv, und bei der Operation wurde eine weite Höhle mit diekflüssigem, schmutzig-gelbem Inhalt gefunden, der massenhaft hellgelbe, talgige Konkremente enthielt.

Weder in dem AbszeBinhalt noch in den Schabseln der Wand wurden Amöben oder Bakterien nachgewiesen. Es wurde hiernach angenommen, dab der Leberabszeb schon lange bestanden hatte. 
Man wird gelegentlich eine einfache kongestive Leberschwellung, wie sie $j a$ auch bei Bazillendysenterie öfters vorkommt, mit AbszeB verwechseln können, wenn auch meist nicht zum Schaden des Kranken.

Gut ist es jedenfalls, mit der Punktion nicht zu lange zu warten.

Man punktiert wohl am besten zuerst mit einer Pravazspritze an der schmerzhaftesten Stelle, und bei negativem Ausfall mit der etwa $12 \mathrm{~cm}$ langen Hohlnadel eines Saugapparates, die mindestens $1 \mathrm{~mm}$ lichte Weite hat, damit der oft sehr dicke AbszeBinhalt die Röhre nicht rerstopfen kann.

Ich finde in der Literatur nur einen Fall, wo infolge Verletzung eines größeren Blutgefäßes eine stärkere Blutung einzutreten drohte. Man ließ die Kanüle zunächst liegen, die Blutung stand, und der Kranke fühlte sich nach dem Blutverluste wesentlich erleichtert (Sachs).

Mir sind in Tsingtau drei Fälle von Leberschwellung bei Dysenterie vorgekommen, in denen wegen wohlbegründeten Verdachts auf AbszeB mehrfach vergeblich mit langen starken Hohlnadeln in die Leber eingedrungen, jedoch nur etwas Blut angesaugt wurde, wonach das Fieber sank und die Beschwerden nachließen. Ähnliches findet sich in der Literatur (Sachs, Nocht u. a.).

Ich sah ferner einen Fall von schmerzhafter LebervergröBerung, mit peritonitischen Reibegeräuschen im rechten Epigastrium, nit wochenlangem Fieber, ohne deutlichen Ikterus. Es wurde etwa $12 \mathrm{mal}$ ergebnislos mit langer, weiter Hohlnadel punktiert. SchlieBlich zeigte das Kleiner- und Härterwerden der Leber, $\mathrm{daB}$ es sich um Cirrhose handelte, was durch die Autopsie bestätigt wurde.

Von den zahlreichen, zum Teil sehr tiefen Punktionen war in und auf der Leber nichts zu sehen.

\section{Behandlung.}

Wichtig ist bei der Dysenteriebehandlung - und zwar handelt es sich hier um beide Ruhrarten - zunächst vollkommene Bettruhe und Warmhalten des Leibes. Besonders bei Schmerzen wird letzteres als sehr wohltätig empfunden. Heiße Wasser- oder besser Leinsamenkompressen sind daher zu empfehlen.

Ein Versuch mit Termophoren, die wegen ihres langdauernden Warmbleibens ganz ausgezeichnete Dienste leisteten, hat sich aus wirtschaftlichen Gründen nach meiner Erfahrung im Krankenhausbetriebe nicht bewährt, da dieselben durch Unachtsamkeit des Pflegepersonals bald unbrauchbar wurden.

Auch in der Rekonvaleszenz und im chronischen Stadium der Ruhr ist das Warmhalten des Leibes von gröBerer Wichtigkeit, als vielfach angenommen wird. Ich habe wenigstens in Tsingtau zur Winterzeit, wo 
wir stets noch eine AnzahI chronischer Fälle in Behandlung hatten, die häufige Beobachtung gemacht, daB nach kälteren Tagen die Stühle mehr Schleim enthielten als sonst. Nachdem den Kranken das Verlassen des Pavillons an kalten Tagen verboten und für eine Heizung der Klosetträume und des Korridors gesorgt war, trat hierin eine Besserung ein. ${ }^{1}$

Der Ruhrkonvaleszent muß eine Leibbinde tragen. Da nun die üblichen Modelle, besonders wenn sie öfters gewaschen sind, bei stärkerer Bewegung des Trägers sich leicht verschieben und dann erst recht eine Erkältung des Unterleibes möglich ist, möchte ich empfehlen, ein 20 bis $25^{\mathrm{cm}}$ breites, etwa $2^{\mathrm{m}}$ langes, ungesäumtes Stück Flanell fest um den Leib $\mathrm{zu}$ legen und mit Sicherheitsnadeln $\mathrm{zu}$ befestigen. Ich bin selbst nach nicht befriedigenden Versùchen mit den üblichen Leibbinden zu dieser einfachen Art übergegangen und habe sie auf einem mehrwöchigen Ritt durch Schantung, wobei reichlich Gelegenheit zum Verschieben der Leibbinde gegeben war, hervorragend bewährt gefunden. ${ }^{2}$

Nicht minder von Bedeutung ist die Diät. Zunāchst darf nur flüssige, warme, schleimige Kost in kleinen Mengen, aber häufig gereicht werden, gegen den Durst Tee. Nach einigen Tagen können Rotweinsuppe mit Sago, Eichelkakao und ähnliches eingeschoben werden, etwas später aufgeweichte alte Semmel oder gerösteter Zwieback.

Viele Ärzte empfehlen warm die Milch. Ich persönlich habe mich indessen nicht davon überzeugen können, daB reine Milch bei frischer Dysenterie irgend einen Vorzug vor der Schleimdiät hätte. Eher würde sie in Form von Suppen mit Mehlzusatz zu geben sein.

Zarteres Fleisch darf erst gestattet werden, wenn die Stühle fäkulent sind und nur noch wenig Schleim enthalten.

Brot darf zunächst nur in Form alter Semmeln oder von Zwieback gegeben werden. Kartoffelbrei und Griespuddings werden nach Verschwinden des Blutes aus den Stühlen meist gut vertragen. GroBe Vorsicht aber ist in der Rekonvaleszenz geboten bezüglich festerer Kost, z. B. des Rindfleisches, der Hülsenfrüchte, der Mohrrüben und des Schwarzbrotes. Der oft sehr rege Appetit bei den Leuten, die eine akute Ruhr eben hinter sich haben, fordert doppelte Achtsamkeit von seiten des Arztes, wenn in einem gröBeren Saal Patienten in den verschiedenen Stadien

\footnotetext{
1 Siehe auch den während der Korrektur dieser Arbeit in Hft. 23 des Archivs für Schiffs- und Tropenhygiene, 1907, erschienenen Vortrag von A. Plehn: Über Sanatorien in den Tropen (S. 736).

${ }^{2}$ Zur Verhütung einer dauernden Gewöhnung an die Leibbinde sind spätere, nach völliger Genesung vorzunehmende, knrz dauernde Kaltwasseranwendungen zu versuchen.
} 
Beobachtungen und Erfahrungen Über Ruhr in Ostasien. 17

der Krankheit liegen. Nur zu leicht kommt es dann vor, daB ein Rekonvaleszent, der kurz vor seiner Entlassung steht und bereits feste Kost erhält, einem anderen, welcher derartige Speisen noch nicht verträgt, aber starken Appetit hat, im Unverstande von seinem Essen gibt. . Oft ist dann allerdings der Stuhl mit seinen unverdauten Bohnen- oder Mrohrrübenstückchen der Verräter.

Über die medikamentöse Ruhrbehandlung ist schon sehr viel geschrieben worden, und fast jedes Jabr erscheinen neue Arbeiten, welche diejenigen Mittel empfehlen, von denen die Autoren in mehr oder weniger viel Fällen besonders gute Erfolge gesehen haben, ein Beweis, daB kein Mittel für alle Fälle als unbedingt sicher wirkend angesehen werden kann.

Die Mehrzahl der Ärzte sind sich jedoch darüber einig, daß beim Beginn der Krankheit, gleichviel ob Bazillen- oder Amöbenruhr vorliegt, zunächst gründlich abgeführt werden muß.

Es ist in der Tat als großer Kunstfehler zu bezeichnen, wenn bei beginnender Dysenterie nicht sofort ein energisch wirkendes Abfübrmittel gegeben wird.

In dieser Hinsicht sind einige aus Tsingtau stammende Zahlen von Wert, wo die Mannschaften der Garnison, sobald Durchfälle bemerkt wurden, auch im Revier sofort Abführmittel (Calomel) bekamen, während die übrige Bevölkerung ausgiebig wirkenden Laxantien gegenüber oft eine gewisse Scheu zeigte, und, falls sie ärztlich nicht behandelt wurde, sich mit selbst besorgten Mitteln, häufig natürlich nur mit Adstringentien oder Opium, zu kurieren versuchte.

Von 16 chronischen Amöbenrubrfällen, die ich dort gesehen habe, kamen nur fünf auf Mannschaften der Garnison, damals etwa 1200 Mann, alle anderen auf die sonstige Berölkerung, damals etwa 800. Offenbar hatte also die erwähnte unrichtige Behandlung zur Verschleppung der Krankheit geführt.

Nachdem die Abführmittel gewirkt haben, werden die verschiedensten anderen Arzneien per os und per clysma verabfolgt, welche zum Teil dem Arzneischatze der Eingeborenen entlehnt sind, z. B. Bälfrucht, DjambuBidji-Blätter, Kô-Sam-Körner, Ipecacuanhawurzel, Granat- u. Simarubarinde.

Aber nur die letzteren drei haben sich Anerkennung bei den europäisch gebildeten Ärzten erworben, wenn auch nicht allgemeine. Letzteres mag mit einer verschiedenen Wirksamkeit der Drogen bei Bazillen- und Amöbenruhr zusammenhängen.

Die Ipecacuanhawurzel wird vielfach als Pulver verordnet, zuweilen auch als AufguB in Form der sogen. Brésillienne. In neuerer Zeit hat man wegen des starken Brechreizes dieser Droge das Emetin derselben 
entfernt und auch hiermit gute Erfolge erzielt, z. B. bei der ostasiatischen Besatzungsbrigade. (Schramm: Infus. Ipec. deemetin. 3/190, stdl. $1 \mathrm{EBl}$.)

Andere haben wieder den ersten oder die beiden ersten Aufgüsse der Brésillienne nicht gereicht, sondern nur den zweiten und dritten bzw. den dritten allein. (Nenninger.)

Ich habe keratinierte Pillen herstellen lassen, um eine Brechwirkung auszuschalten. Meist gelang dies, so daB in schweren Fällen bis zu 6 grm Ipecacuanha täglich ohne. Erbrechen gegeben werden konnten; zuweilen lösten sich aber bei zu dünnem Keratinüberzuge die Pillen entweder schon im Magen und führten zu Erbrechen, oder sie passierten bei zu dicker Keratinschicht ungelöst den Darm. Vielleicht könnten sie bei fabrikmäBiger Herstellung, welche eine gleichmäBige Keratinisierung besser gewährleistet als die Anfertigung mit der Hand, gute Dienste leisten. ${ }^{1}$ Buchanan, Duncan und Moulyneux behaupten, daB die Eingeborenen (in ibren Fällen Indier und Chinesen) die Ipecacuanha besser vertragen als die Europāer; dasselbe sagte mir ein Arat in Penang.

Die Droge soll übrigens von ihrer Wirksamkeit verlieren, wenn sie in gepulvertem Zustande anstatt in größeren Stücken aufbewahrt wird.

Vom Granatbaume wird die Rinde der Äpfel (Paulun, v. Wedel), der Aste und der Wurzel (Gelpke) zu Auszügen und Abkochungen verwendet.

Paulun in Shanghai legt Wert darauf, daB die Rinde von unreifen Äpfeln stammt, die er mit der gleichen Menge Simaruba durch süßen Sherrywein ausziehen läßt. v. Wedel in Singapore läBt nach anfänglichen Calomelgaben von jenen Drogen und Chinin, alles zu gleichen Teilen, eine Abkochung herstellen. Müller in Hongkong gibt drei Fluidextrakte gemischt, die, soweit ich erfahren konnte, im wesentlichen aus den eben erwähnten Drogen hergestellt sind. In den wenigen Fällen, wo ein kleineres Versuchsquantum des Müllerschen Mittels in Tsingtau geprüft werden konnte, hat es ganz gute Dienste geleistet.

Neuerdings berichtet Viereck aus dem Hamburger Institut über sehr gute Erfolge mit Simaruba-Granatrindendekokt bei Amöbendysenterie.

Das Wismut wird ebenfalls vielfach gebraucht. Während Schüffner und Künen (Amöbenruhr), sowie ich selbst (Bazillenruhr) keine ermatigenden Wirkungen davon gesehen haben, wird es von anderer Seite (A. Plehn, Nenninger) wieder wärmer empfohlen. Der Grund hierfür ist vielleicht in der verschiedenen Größe der Gaben zu suchen. Nen-

\footnotetext{
${ }^{1}$ Über die Wirkung der von Dr. Kades Apotheke in Berlin jetzt hergestellten Antidysenteriepillen, welche im wesentlichen aus emetinfreier Ipecacuanha bestehen sollen, habe ich nur geringe Erfahrungen. Vielleicht leisten sie gute Dienste.
} 
ninger verordnete auf der "Gera" eine Emulsion von ${ }^{10} / 100$, die er morgens nüchtern etwa 1 Woche lang nehmen lieB. Auch Böhm hat in letzter Zeit in Tsingtau mit großen Wismutdosen (10 mal täglich $1 \mathrm{grm}$ ) sehr gute Erfolge gehabt.

Die Schwartzschen Antidysenteriepillen haben sich weder in Tsingtau, noch bei den Truppenärzten im Norden Anerkennung erringen können.

Von mancher Seite (A. Plehn) ist dem Calomel in kleinen Dosen das Wort geredet worden. Andere wieder warnen vor längerem Calomelgebrauch (Schüffner und neuerdings Sinnhuher).

Wir sahen in Tsingtau nach häufigen kleinen Calomelgaben keine Erfolge, dagegen öfters Mundfäule (trotz Mundpllege).

Die englischen Ärzte Rogers und Buchanan empfehlen nach ihren Erfahrungen in Indien die salinischen Mittel, und zwar nicht nur für den Beginn, sondern auch den weiteren Verlauf der Dysenterie. Buchanan gibt Magnesium oder Natrium sulfuricum in Dosen von etwa $4 \mathrm{grm}$ mehrere Male täglich in einem EBlöffel Fenchelwasser, bis die Stühle wieder hotig werden, und hat mit diesem Mittel - es scheint sich bei seinen Patienten meist um Bazillenruhr gehandelt zu haben - anscheinend gute Erfolge erzielt.

Vielfach in Ostasien angewendet ist die Rhein sche Mixtur (Simarubarinde und Zimt), welche auch im Marine-Feldlazarett zu Peking gute Dienste geleistet hat.

Schüffner und sein Mitarbeiter Künen, welchen auf Sumatra ein reiches Material, besonders an Amöbenruhr, zur Verfügung stand, gaben zunächst $0.5 \mathrm{grm}$ Calomel, dann eine Emulsion von Rizinusöl und Gummi arabicum, der sie nach Maurers Vorgange $1 / 2$ Prozent Calcium carbonicum (Kreide) zusetzten, und waren sehr befriedigt hiervon. Half dies nicht, so wendeten sie Glaubersalz, in chronischen Fällen Simaruba, Ratannhiatinktur und Tannalbin an. Tannigen hat sich bei ihnen nicht bewährt. (Für diese Mitteilungen bin ich meinem Freunde Schüffner zu Dank verpflichtet.)

Französische Ärzte haben auch Jodoform per os gegeben; andere Resorcin, Kreosot, Salol, auch Salicylsäure mit Wismut und Opium.

Während in Tsingtau in früheren Jahren nach gründlicher Darmentleerung durch 1 bis $2^{\mathrm{grm}}$ Calomel und nachfolgender groBer Rizinusdosis (zur Verhütung von Vergiftung) morgens und abends je 2 grm Ipecacuanha gereicht wurden, habe ich eine Zeitlang die emetinfreie Ipecacuanha, später die bereits erwähnten Keratinpillen versucht, bis ich schlieBlich mit stündlichen Grammdosen von Tannalbin unter Vermeidung des Brechreizes gute Erfolge hatte. Das vorherige gründliche Abführen mit Calomel und Rizinusöl behielt ich bei. 
Auch Simarubawein wurde viel gegeben. Ich selbst habe indes, vielleicht wegen zu kleiner Dosen, keine sehr auffallende Wirkung davon gesehen, dagegen gelegentlich in leichteren Fällen von Rhizoma Tormentillae (mehrmals täglich $1 \mathrm{grm}$ ).

Gelegentlich wurde auch Tannigen oder Tannocol in großen Dosen mit Erfolg gegeben, während das Tannoform mehrfach als fester Klumpen in den Stühlen wiedererschien. Drohte Verstopfung einzutreten, so wurden die Tannalbingaben auf dreimal täglich $1 \mathrm{grm}$ herabgesetzt, und nebenbei jeden oder jeden zweiten Morgen ein EBlöffel Rizinus verabfolgt: Der Stuhl kann bei Ruhrrekonvaleszenten in kurzer Zeit so fest werden, dab er die noch zarten Schleimhautnarben wieder aufreiBt, was aus gelegentlichen Beimengungen von Blut ohne Schleim zum geformten Kot zu schlieBen ist.

Auch kann man nie wissen, ob die Ruhrkeime trotz der makroskopisch normalen Stühle nicht doch noch im Darm vorbanden sind, so $\mathrm{daB}$ bei mangelhafter Stuhlentleerung leicht eine Neuentwicklung, besonders bei Druck ron Kotballen auf die Schleimhaut, wodurch eine Angriffsstelle geschaffen wird, stattfinden kann. Denn, daß Ruhrbazillen ohne klinische Erscheinungen im Darme vorhanden sein können, ist nach den Untersuchungen von Conradi u. a. als sicher anzunehmen; und für die Amöbenruhr kann man ähnliche Verhältnisse deshalb voraussetzen, weil LeberabszeBkranke öfter von ihrer Ruhr überhaupt nichts geahnt haben wollen.

Schon hieraus ergibt sich, daß darmlähmende Stopfmittel, wie Opium, im allgemeinen zu verwerfen sind. Nur geringe Gaben davon dürfen für eine kurze Wirkung, z. B. bei der Ipecacuanhakur oder groBer Unruhe und quälendem Tenesmus, gereicht werden.

Vielfach empfohlen, und zwar für beide Ruhrarten, werden die Einläufe, und hier zeigt sich dieselbe Vielartigkeit der Mittel, wie bei der Behandlung per os. Auch hier kann aus ihrer großen Zahl geschlossen werden, daß kein Mittel für alle Fälle hilft.

Mit den von Lösch und Councilman und Lafleur empfohlenen Karbol- bzw. Sublimatklysmen wird sich heute niemand mehr befassen. Es wurden dann weiter versucht Lösungen bzw. Emulsionen von Kreosot (Billet, Zanardini), Kupfersulfat (Moulden, Sandwith), Borsäure (Sandwith, Duncan), Jodoform (Me yer), Jodoform und Wismut (van Brero), Höllenstein (Le Dantec, Desai), Chinin (Councilman und Lafleur, Rogers, Schüffner und Künen), Tannin (Kartulis, Schüffner und Künen).

Bei der ostasiatischen Besatzungsbrigade wurde Höllensteinlösung $1: 750$, später, wenn das Blut verschwunden war, Tanninlösung 15:750 mit 30 grm Amyl. trit. angewendet. 
Beobachtungen und Erfahrungen Über Rohr in Ostasten. 21

Auf der „Gera“ sowohl, wie auf den deutschen Kriegsschiffen in 0stasien, sah man gute Erfolge von $1 / 2$ prozent. Tanninlösungen nach Kartulis.

In Tsingtau wurden Höllenstein-, Tannin-, Kaliumpermanganat- und essigsaure Tonerdelösung versucht, meist mit nicht sehr auffallendem Erfolge. Gegen Höllenstein- und Tannineinläufe batten die Kranken wegen der Schmerzhaftigkeit öfter einen Widerwillen.

Nach meinem Dafürhalten läBt man im akuten Stadium der nordchinesischen Ruhr die Einläufe am besten ganz fort und die Kranken in Ruhe. Nur bei sehr heftigen Tenesmen empfehlen sich Klistiere mit 1 Liter warmen Tees. Dieses alte ostasiatische Missionarsmittel wirkt angenehm beruhigend.

Im chronischen Stadium dagegen kann man die verschiedenen Mittel im Klistier versuchen, und zwar mehrmals am Tage eine EingieBung machen lassen. Die Benutzung eines längeren Darmrohres ist unnötig, ein gewöhnlicher Irrigatoransatz genügt. Naunyn, Schüle und Sternberg behaupten auch, dab längere weiche Sonden sich in der Ampulle des Rektums aufrollen. Festere Sonden dürften gefährlich sein.

Die Einlaufsflüssigkeit kann, wie Schüle mit Wismutemulsion und Röntgenstrahlen nachgewiesen hat, bei Knie-Ellenbogenlage bis zur Blinddarmklappe hinaufdringen.

Bei sehr schwerer, gangränöser Ruhr ist natürlich, ganz abgesehen von keinem zu erwartenden Erfolge, die Anwendung von Einläufen nur mit gröBter Vorsicht erlaubt. Sheldon Amos widerrät sie überhaupt.

Eine andere lokale Behandlung, dje aber nur bei Geschwüren des untersten Darmabschnitts anwendbar ist, hat v. Wedel in Singapore öfter versucht. Er stopft das Rectum mit Jodoformgaze aus (mūndliche Mitteilung).

Eine Zukunft hat vielleicht bezüglich der bazillären Dysenterie die Serumbehandlung.

Nachdem schon Shiga in Tokio ein Serum hergestellt hatte, mit dem er die Mortalität auf 7 Prozent verminderte, während von den medikamentös Behandelten 22 Prozent starben, gelang es auch bei einer geringeren Anzahl von Fällen Kruse, die Sterblichkeit von 11 auf 5 Prozent herabzusetzen.

Ảhnliche Resultate hatten Gabritschewsky und Rosenthal, ferner Lüdke, sowie neuerdings Kraus und Dörr. Freilich haben alle diese Forscher nur mit einem unter Verwendung des Bacillus Shiga-Kruse hergestellten Serum gearbeitet, welches antitoxische Eigenschaften hat.

Nach den Untersuchungen von Kraus und Dörr bildet der Bacillus Flexner kein lösliches Toxin, so daß es diesen beiden Forschern nicht 
BöSE:

möglich erscheint, ein wirksames antitoxisches Heilserum für die Flexnerruhr zu erlangen. Die Zukunft wird das weitere lehren.

Shiga stellt neuerdings ein polyvalentes Serum her, welches gegen fünf verschiedene Ruhrbazillentypen wirksam sein soll.

Chronisch Kranke, besonders mit Amöben infizierte, werden am besten nach Europa geschickt, wo sie unter günstigeren Bedingungen leben und zweifellos bessere Heilungsaussichten haben als in den Tropen und Subtropen.

Bezüglich der Behandlung der Komplikationen ist zunächst bei Bazillenruhr eine genaue Utberwachung des Herzens von Wichtigkeit. Der Gefäßapparat ist durch die Toxine gefährdet, so da $B$ rechtzeitig Exzitantien gegeben werden müssen (Nenninger). Bei stürmischem Beginn der Krankheit mit großer Postration des Patienten, zumal bei Kindern und Greisen, kann zweifellos hierdurch gelegentlich das Leben gerettet werden. Bei fortgeschrittener Ruhr aber, wo eine weitgehende Zerstörung der Darmschleimhaut stattgefunden hat, werden auch Anregungsmittel in der verschiedensten Form nur vorübergehend wirksam sein.

Die Gelenkaffektionen reagieren nicht auf Salicyl, werden daher am besten nur physikalisch behandelt.

Bei den einfachen Leberentzündungen empfiehlt Krämer Trockendiät. Wir behandelten derartige Fälle in Tsingtau mit Kälte und salinischen Abführmitteln, sowie leichter, flüssiger Diät. In drei Fă̈llen sahen wir, wie schon erwähnt, von Leberpunktionen, die mit weiter und langer Hohlnadel zu diagnostischen Zwecken unternommen wurden, einen auffallenden Erfolg.

Der LeberabszeB gehört im allgemeinen der chirurgischen Behandlung. Zwar hat Manson mit dem von ihm angegebenen Troikar, dessen Kanüle später durch ein weiches Gummirohr ersetzt wird, verhältnismäBig gute Erfolge gehabt, desgleichen Turnbull; zwar schreibt auch Macleod in Shanghai, daB er mit dem Einlegen einer Metallkanüle mit ovalem Lumen, wodurch die Rippenresektion vermieden werden kann, gute Resultate erreicht habe; dennoch werden die Fälle, wo diese Methoden in Anwendung zu bringen sind, auf sehr kachektische Kranke beschränkt bleiben, denen man selbst eine Äthernarkose, die von Sachs und Goebel empfohlen wird, nicht mehr zumuten kann. Auch in Fällen, wo keine Assistenz verfügbar ist, dürfte gelegentlich die Punktionsdrainage gute Dienste leisten.

Der AbszeBinhalt ist aber oft so dick und so reich an gröberen Gewebstrümmern, daß eine Verstopfung der Kanüle selbst bei weitem Lumen unvermeidlich sein kann. 
Die meisten Autoren äußern sich daher gegen diese Art der AbszeBbehandlung und ziehen eine ausgiebige Eröffnung der Höhle mit dem Messer vor.

Früher wurde, um die Bildung von Adhäsionen abzuwarten und so die Bauch- und Brusthöhle zu schützen, zweizeitig operiert. Jetzt aber wird in der Regel nach erfolgreicher Probepunktion gleich zur Eröffinung des Abszesses geschritten. Langenbuch empfiehlt, nach Durchtrennung der Bauchdecken erst den AbszeBinhalt auszusaugen und dann die Leber an das Peritoneum bzw. die Pleura anzunähen. Die Nähte sollen dann besser halten. Die meisten anderen Operateure aber stopfen nach Freilegung der Leber und, wenn nötig, Rippenreseition die ganze Umgebung mit Gaze aus, öffnen den AbszeB, entleeren den Inhalt und nähen dann die Leber an (Sachs, Goebel, Mac Callum u. a.). Auf diese Weise wird ein Hineinfließen des Abszeßinhaltes in die Leibeshöhlen verhindert. Rogers empfiehlt dann noch Ausspülung der Abszeßhöhle mit Chininlösung.

In Tsingtan wurde, abgesehen von einem Falle, wo die Punktionsdrainage unter Erweiterung der Offnung mit Laminariastiften gemacht und reichlicher $\triangle \mathrm{AblluB}$ erzielt wurde, eine breite Offnung angelegt.

Bei multiplen Abszessen, welche die ganze Leber durchsetzen, ist natürlich eine Operation ron vornherein als aussichtslos anzusehen. Dennoch wird man sich nicht abhalten lassen, sobald nach erfolgreicher Operation eines Abszesses ein weiterer in einiger Zeit sich zeigen sollte, auch diesen zu eröffnen. Es ist ein Fall bekannt, wo nacheinander in bestimmten Zwischenräumen drei Abszesse erfolgreich operiert wurden (Schlayer). Als eigentliche multiple Abszesse wird man dieselben bei ihrer geringen Zahl aber nicht bezeichnen können.

Die Folgekrankheiten der Ruhr müssen je nach den Symptomen behandelt werden.

Einer Schlaffheit des Darmes, die gelegentlich eintritt, kann durch vorsichtige Massage, wie das in Tsingtau öfters geschah, vorgebeugt werden. Natürlich ist die Bedingung hierfür, daß keine Anzeichen für Ruhrgeschwüre mehr rorhanden sind.

Bei Darmadhäsionen leisten vielleicht Moor- und Solbäder gute Dienste. Die Diät sei zur Verhütung von Stuhlverstopfung vorwiegend vegetarisch.

Blutarmen und nervösen Rekonvaleszenten ist ein Ortswechsel, Aufenthalt im Gebirge oder in schwereren Fällen Rückkehr nach Europa und Aufsuchen eines geeigneten Badeortes zu empfehlen. 
Morbiditāt.

Die Krankheitsziffern bezüglich beider Ruhrarten stellen sich in verschiedenen Gebieten des östlichen Asiens wie folgt:

In ganz Indien erkrankten von den europäischen | 1900 und eingeborenen Truppen . . . . . 1901

Presidency-Distrikt . . . . . . . . . . 1900

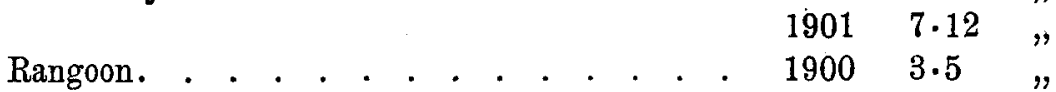

19014.48,

Peshawar . . . . . . . . . . . . 19001.27 ",

19011.04,

Madras . . . . . . . . . . . $1900 \cdot 1.7$ "

$1901 \quad 1.45$,

Bombay . . . . . . . . . . . . . $1900 \quad 3.5$ ",

$1901 \quad 1 \cdot 1 \quad "$

Sumatra (farbige Arbeiter der Senembah-Plan- ) 18984.8 ", tagen) . . . . . . . . . . . . 19051.5 "

Französische Kolonialtruppen in China und

Indochina im Jahre 1903:

Europāer:

Besatzungstruppen im Norden . . . . . $2 \cdot 2$ ",

Annam-Tonkin . . . . . . . . . . 8.2 ",

Cochinchina . . . . . . . . . . 9.6"

Farbige:

Annam-Tonkin . . . . . . . . . $1 \cdot 3$ "

Cochinchina . . . . . . . . . . . 5.4 "

Ostas. Exp.-Korps der Deutschen Marine - . . . 6.2 "

Kiautschou-Truppen . . . . . . . . . 1898/99 0.6 ",

$1899 / 00 \quad 9 \cdot 5 \quad$,

$1900 / 01 \quad 8.3 \quad$ "

$1901 / 02 \quad 10.3 \quad$,

$1902 / 03 \quad 4.8 \quad$,

$1903 / 04 \quad 4.7 \quad$,

$1904 / 05 \quad 5 \cdot 3 \quad$ "

Die besondere Bevorzugung einer Rasse bezüglich der Dysenterieerkrankungen hat sich nach vielen Beobachtungen im allgemeinen nicht herausgestellt. 
In Indien leiden sowohl die Europäer wie die Eingeborenen in bestimmten Gegenden viel unter Rulr. Nach Buchanan grassiert die Bazillenruhr so sehr in den indischen Gefängnissen, daB die meisten Neueingelieferten dort erkranken, freilich gemeinhin nur leicht.

In Singapore soll unter den Europäern, besonders aber den Eingeborenen viel Amöbenruhr herrschen (Finlaysen, mündliche Mitteilung).

Auf Sumatra erkranken die Arbeiter der Senembah-Plantagen häufig an Dysenterie, auch bei den Europäern wurde in letzter Zeit viel Ruhr, aber von mehr schleichendem Charakter beobachtet (Schüffner, briefliche Mitteilung). Es handelt sich dort vorwiegend um Amöbenruhr.

In Annam-Tonkin und Cochinchina jedoch erkrankten 1903 ganz erheblich viel mehr Europäer als Eingeborene (Bericht des französischen Kriegs- und Kolonialministeriums 1903).

Im Faber-Hospital zu Tsingtau kam bei den chinesischen Kranken so gut wie nie ein Ruhrfall zur Beobachtung. Daraus darf man aber noch nicht schließen, daB die Chinesen nie oder wenig an Dysenterie leiden. Sie lassen sich daran nur nicht von europäischen Ärzten, welche sie mehr für chirurgisehe Krankheiten konsultieren, behandeln, sondern gehen zu ihrem Chinesendoktor oder behandeln sich selbst. Wenn man Chinesenaborte oder Kotablegungsstellen in der Nähe von Arbeitsplätzen ansieht, so findet man dort viele durchfällige Stühle. Der Chinese ist aber in seiner Diät (Reisesser) viel vorsichtiger als der Europäer, und hierin ist vielleicht der Grund zu suchen, warum er, wenn er sich mit Dysenterie infiziert hat, in der Regel nicht so schwer erkrankt.

Für den Leberabszeß scheint die farbige Rasse gegenüber der weißen bei flüchtiger Betrachtung der Morbiditätszahlen weniger disponiert zu sein. Ein gewisser Schutz für jene mag in den tropischen Ländern insofern vorhanden sein, als sie nicht unter Leberkongestionen derart zu leiden hat wie die Europäer, besonders die kürzlich aus einem kühleren Klima zugereisten.

Der Hauptgrund aber, weshalb der Eingeborene so verhältnismäBig selten an LeberabszeB erkrankt, ist wohl in seiner gröBeren Enthaltsamkeit bezüglich des Alkohols zu suchen. Vielen Tropenärzten ist es aufgefallen, daB Alkoholiker ungleich öfter an LeberabszeB erkranken als Abstinente (Sachs, Kelsch und Kiener, Göbel, Rogers, Fiebig, Mac Callum, Krämer, Schüffner).

Mac Callum berichtet, da $B$ in Ländern, wo der LeberabszeB unter den Eingeborenen sonst selten ist, gelegentlich diejenigen unter ihnen erkranken, welche durch den Verkehr mit Europäern zum SpirituosengenuB gekommen sind.

Schüffner, der auf Sumatra viel Leberabszesse gesehen hat, teilte mir mit, daB bei den auf den Senembah-Plantagen arbeitenden abstinenten 
BösE:

Chinesen und Javanen der LeberabszeB sehr selten ist, bei den Tamils dagegen, welche starke Schnapstrinker sind, häufiger. Und unter den Europäern seien es auch meist die Freunde alkoholischer Getränke, welche erkranken.

Von den in Tsingtau beobachteten Fällen gilt zum Teil dasselbe.

AuBerdem disponieren aber ganz zweifellos Utberanstrengungen (Rogers u. a.) und Traumen (Sachs).

Die Seltenheit, mit welcher der LeberabszeB im allgemeinen beim weiblichen Geschlecht und bei Kindern beobachtet wird, hängt wohl auch mit dem eben Ausgeführten zusammen.

In Tsingtau freilich wurden unter 9 Fällen 3 bei Frauen beobachtet. Eine derselben (Prostituierte), war aber mit ziemlicher Sicherheit Trinkerin, eine andere Gravida, also auch veränderten Zirkulationsverhältnissen in der Leber ausgesetzt.

Nach einigen Autoren sollen Frauen überhaupt an Ruhr weniger als Männer erkranken. Nach den Tsingtauer Erfahrungen sind jedoch beide Geschlechter gleich disponiert.

Die große Ruhrmorbidität unter den Kindern ist bekannt (Bornträger, Lüdke). Auch in Tsingtau konnten wir die Beobachtung mashen, daB gelegentlich Kinder auffallend viel erkrankten, oft vielleicht durch Gebrauchsgegenstände, die sie in den Mund zu stecken pflegen, infiziert.

\section{Mortalität.}

Die Sterblichkeit an Dysenterie ist nach dem Alter, der Widerstandskraft, den einzelnen Ländern, auch nach der Art der Erreger, verschieden. Kinder und Greise erliegen der Krankheit am leichtesten.

$\mathrm{DaB}$ andere gleichzeitig bestehende Krankheiten, z. B. die Malaria, Ankylostomiasis, Sprue, die Widerstandskraft des Kranken erheblich beeinträchtigen können, ist bekannt. In Annam-Tonkin erliegen von den eingeborenen Soldaten besonders die Opiumraucher der Krankheit (Bericht des französischen Kriegs- und Kolonialministeriums, 1903).

In Singapore sollen die Eingeborenen, welche häufig erst in späteren Stadien der Erkrankung ärtliche Hilfe aufsuchen, oft an Dysenterie zugrunde gehen (Finlaysen), während die Europäer, welche rechtzeitig sich in Behandlung begeben, seltener daran sterben (v. Wedel).

In Shanghai soll die Dysenteriesterblichkeit unter den Europäern keine groBe sein. Utber diejenige unter den Chinesen ist mir nichts bekannt.

Aus T'singtau ist mir nur ein Fall erinnerlich, wo ein Chinese der Ruhr (Amöben-) erlegen ist. 
Beobachtungen und Erfahrungen Über RUhr tn Ostasien. 27

In der nachstehenden Übersicht sind zunächst mehrere Mortalitätszahlen aus Europa, wo es sich wohl ausschlieBlich um Bazillenruhr handelte, angegeben, dann einige aus dem östlichen Asien.

\begin{tabular}{|c|}
\hline Barmen . \\
\hline Döbe \\
\hline
\end{tabular}

In ganz Indien ${ }^{1}$ starben von den europäischen und eingeborenen Truppen:

\begin{tabular}{|c|c|c|c|}
\hline & 1900 & $3 \cdot 7$ & rozent \\
\hline & 1901 & $4 \cdot 8$ &, \\
\hline Presidency-Distrikt & 1900 & 7.5 & $n$ \\
\hline & 1901 & $6 \cdot 6$ & . \\
\hline Rangoon . & 1900 & $4 \cdot 0$ & $"$ \\
\hline & 1901 & $2 \cdot 0$ & $"$ \\
\hline Peshawar & 1900 & 0.0 & $"$ \\
\hline & 1901 & $10 \cdot 0$ & $n$ \\
\hline Madras (europäische Truppen) . & 1894 & $6 \cdot 2$ & 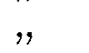 \\
\hline Bombay . . . . . . . . & 1894 & $5 \cdot 2$ & $\because$ \\
\hline Ceylon (Castellani). & 1902 & $30 \cdot 0$ & 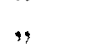 \\
\hline Sumatra (Schüffner) & 1898 & $55 \cdot 9$ & 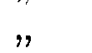 \\
\hline & 1904 & $25 \cdot 8$ & , \\
\hline & 1905 & $14 \cdot 3$ & " \\
\hline Japan (amtliche Angabe) . . . & 1905 & $22 \cdot 7$ & ” \\
\hline Ostasiat. Exped.-Korps der Armee & & $4 \cdot 0$ & $"$ \\
\hline " Besatzungsbrigade . . . & $1902 / 03$ & $2 \cdot 6$ & $"$ \\
\hline & $1903 / 04$ & $2 \cdot 9$ & $"$ \\
\hline Epidemie an Bord S. M. S. „,Arkona“ & 1862 & $13 \cdot 8$ & $"$ \\
\hline$" \quad, \quad$ "Vineta & 1881 & $1 \cdot 2$ & $"$ \\
\hline Ostasiat. Marine-Exped.-Korps . . & $1900 / 01$ & $6 \cdot 5$ & $n$ \\
\hline Kiautschou-Truppen . . . . & 1898 & $25 \cdot 0$ & $"$ \\
\hline & $1899 / 00$ & $2 \cdot 1$ & $"$ \\
\hline & $1900 / 01$ & $7 \cdot 7$ & $"$ \\
\hline & $1901 / 02$ & 0.5 & 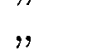 \\
\hline & $1902 / 03$ & 0.0 & 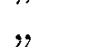 \\
\hline & $1903 / 04$ & 0.0 & $"$ \\
\hline & $1904 / 05$ & 0.9 & $"$ \\
\hline
\end{tabular}

Die hohe Mortalitätszahl der Kiautschou-Truppen des Jahres 1898 hängt wohl mit der kurz nach der Besitzergreifung noch mangelhaften

$1 \mathrm{Ob}$ diese Zahlen sich groBenteils auf Bazillenruhr beziehen, ist nicht festzustellen, wenn auch nicht unwahrscheinlich. 
Unterbringung zusammen. Zunächst hatten die Truppen chinesische Soldatenlager bezogen, die erst allmählich einigermaßen saniert werden konnten.

Die größte Sterblichkeit an Ruhr hat danach 1898 unter den Arbeitern der Senembah-Plantagen auf Sumatra geherrscht, wo, wie überhaupt anscheinend auf den Sundainseln, die Amöbenruhr die vorherrschende Art ist. Sie scheint auch im allgemeinen diejenige zu sein, welche die meisten Menschenleben fordert.

Man sieht aber auch zugleich an den mir von Hrn. Dr. Schüffner freundlichst mitgeteilten Zahlen, was ein energischer Kampf gegen die Seuche von seiten des Arztes und der Plantagen-Verwaltung zu leisten vermag. Seitdem immer wieder auf eine Hospitalbehandlung aller ruhrkranken Arbeiter gedrungen worden ist, ist es gelungen, innerhalb von 7 Jahren die Mortalität von 56 Prozent auf 14 Prozent herabzusetzen.

Breitenstein teilt aus Niederländisch-Indien mit, daB dort in den Jahren 1819 bis 1831 von allen Todesfällen 41 Prozent auf Dysenterie kamen. Bis 1895 war diese Zahl auf $6 \frac{1}{2}$ Prozent gesunken.

\section{Prognose.}

Für ganz frische unkomplizierte Fälle, die sofort in geeignete Behandlung kommen, ist die Prognose beider Ruhrarten bezüglich des Lebens im allgemeinen als leidlich gut $z u$ bezeichnen, und zwar werden die nördlichen Breiten eine noch bessere Aussicht auf Heilung geben, als die Tropen.

Zweifelhaft aber wird die Prognose, sobald ein schon durch Krankheit, Überanstrengung oder Exzesse geschwächter Körper befallen wird, oder sich Komplikationen hinzugesellen, ebenso, wenn der Kranke gar nicht oder in ungeeigneter Weise behandelt wird. Die Amöbenruhr bietet hier in der Regel schlechtere Heilungsaussichten als die bazilläre. Sobald ein LeberabszeB oder eine Blinddarmentzündung hinzutritt, wird der Zustand natürlich stets ein ernster.

Bezüglich der chronischen Ruhrfälle, wenn Amöben die Erreger sind, ist die Prognose stets mit Vorsicht zu stellen, auch wenn die Krankheit scheinbar milde verläuft.

So erkrankte in Tsingtau ein Herr an LeberabszeB, der angeblich nie an Ruhr gelitten hatte. Erst nach seinem Tode hörte man, daB er doch hin und wieder gegen Darmstörungen ein Glas Glühwein getrunken hätte. Ein anderer hatte sich stets ambulant wegen seiner Darmstörungen behandeln lassen und erkrankte ebenfalls an Leberabszeb.

In einem weiteren Falle, in dem es sich um eine schleichende, bald fast symptomlose, dann wieder verschlimmerte Amöbenruhr handelte, kam es später zu einer schweren Blinddarmentzündung. 
Beobachtungen und Erfahrungen Über Ruhr in Ostasien. 29

\section{Ätiologie.}

Bazillenruhr. Bezüglich der Erreger der bazillären Dysenterie ist allmählich, in letzter Zeit besonders durch Shiga und Kruse, sowie dessen Mitarbeiter, einige Klarheit geschaffen worden. Es gilt jetzt als feststehend, daB auBer dem bekannten Bacillus Shiga-Kruse auch andere verwandte Typen die Ruhr hervorrufen können. Kruse nennt sie Pseudo-, Castellani Paradysenteriebazillen.

Einige Autoren neigen zu der Ansicht, daß auch das Bacterium coli commune und andere gewöhnlich harmlose Darmbewohner unter gewissen Bedingungen sich eine Virulenz aneignen können, so daß sie $\mathrm{Ruhr}$ hervorzurufen imstande sind (Quincke, Fscherich u. Pfaundler u. a.).

Der Bacillus Shiga-Kruse ist bisher in Indien, China und Japan gefunden worden, der Bacillus Flexner auf den Philippinen und in China. Es bleibt abzuwarten, ist aber wohl anzunehmen, daB die Isolierung beider Arten, die sich auch sonst sowohl in Europa wie in Amerika, zum Teil auch in Afrika gefunden haben, auch in Ostasien dort, wo es bisher noch nicht geschehen ist, in absehbarer Zeit gelingen wird.

Shiga stellte fest, daB in Japan, wo in früheren Jahren der ursprüngliche sogenannte echte Dysenteriebacillus häufig zu finden war, derselbe jetzt erheblich seltener geworden ist. Man konnte ihn 1905 in Tokio nur in etwa 200 Fällen isolieren.

Die Eigenschaften des Bacillus Shiga-Kruse und Flexner sind bekannt. Von verwandten Typen, die aus Dysenteriestühlen gezüchtet wurden, sind auch bereits mehrere beschrieben worden.

Castellanis Paradysenteriebazillen wuchsen auf Agar üppiger als die Shiga-Kruse-Bazillen und bildeten in Lackmusmolke mehr und dauernd Säure: Die Molke wurde in 12 Stunden rot und blieb so über 2 Nonate lang. Sie wurden vom Blute der betreffenden Patienten, aber nicht von dem der übrigen Ruhrkranken agglutiniert.

Amako in Kobe fand in einem der letzten Jahre im Juli nur Varietäten jenes Mikroorganismus, im August vorwiegend diesen selbst, dann nahmen mit Rückgang der Epidemie beide Arten an Zahl ab, und schließlich konnten wieder nur Varietäten gefunden werden (Shiga).

Ohno unterschied mit Hilfe der Gärung in den mit rerschiedenen Zuckerarten hergestellten Nährböden 16 Abarten von Ruhrbazillen, von denen 6 Gas bildeten, 10 nicht (Shiga).

Shiga hat dann schlieBlich fünf Gruppen aufgestellt, die sich bezüglich der Indolbildung und der Vergärung der genannten Substrate wie folgt verhalten: 


\begin{tabular}{|c|c|c|c|c|c|c|c|}
\hline $\mathrm{T} \boldsymbol{s} \mathrm{pus}$ & 홀 & 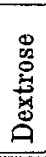 & $\begin{array}{l}\text { 泀 } \\
\text { 曾 }\end{array}$ & 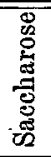 & 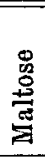 & 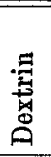 & 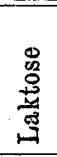 \\
\hline I (Urig.-Stamm) & - & + & - & - & - & - & - \\
\hline U & \pm & + & + & - & - & - & - \\
\hline III & + & + & + & + & - & - & - \\
\hline IV & + & + & + & + & + & + & - \\
\hline $\mathrm{V}$ & + & + & \pm & + & + & + & - \\
\hline
\end{tabular}

Die Agglutination jener Stämme mit den verschiedenen durch sie gewonnenen Seris (Kaninchen) verhält sich, wie folgt:

\begin{tabular}{c||r|r|r|r|r}
\hline \hline $\begin{array}{c}\text { Bazillen - } \\
\text { Typus }\end{array}$ & \multicolumn{5}{|c|}{ S e r u m } \\
\hline I (Orig.-Stamm) & 1600 & II & III & IV & V \\
\hline II & 400 & 6400 & -25 & -25 & -25 \\
III & -25 & 6400 & 6400 & 800 & 400 \\
IV & 100 & 400 & 400 & 6400 & 800 \\
V & -25 & 100 & 400 & 6400 & 3200
\end{tabular}

Danach wird der Bacillus Shiga-Kruse nur von seinem eigenen, nicht aber von dem Serum der anderen vier Typen agglutiniert. Die übrigen Typen werden von allen Seren agglutiniert mit Ausnahme des Typus III und V, welche von Shiga-Serum nicht beeinfluBt werden.

Kruse und seine Mitarbeiter haben neuerdings ebenfalls verschiedene Typen von ruhrähnlichen Bazillen aufgestellt, die sie Pseudodysenteriebazillen nennen. ${ }^{1}$

Ich habe in Tsingtau bei sehr vielen bakteriologischen Ruhrstuhluntersuchungen nur einmal den Bacillus Shiga-Kruse (Stamm Kolter) gefunden, welcher hier in Deutschland mit künstlichem, hochwertigem Serum durch positive Agglutination (1:3000 makroskopisch innerhalb $1 / 4$ Stunde) identifiziert wurde.

Einen Flexner-Stamm zu finden, gelang mir nicht, dagegen drei andere Typen, von denen einer, „Beck", dem Kruseschen Stamm B und D nahe verwandt, zwei, "Müller" und „Geisinger", zwar Pseudodysenteriestämme im Sinne Kruses, aber von allen Typen dieses Forschers erheblich verschieden sind, da sie nicht von den betreffenden Seris agglutiniert werden (Für diese briefliche Mitteilung bin ich Hrn. Prof. Kruse, dem ich die Stämme übersandt hatte, zu Dank verpflichtet).

${ }^{1}$ Kruse, Rittersha us, Kemp und Metz, Dysenterie und Psendodysenterie. Diese Zeitschrift. 1907. Bd. LVII. Erst während der Drucklegung dieser Arbeit zu meiner Kenntnis gelangt. 
Beobachtungen und Erfahrungen über Rugr in Ostasten. 31

Die Tsingtauer Kulturen wurden im Sommer 1904 auf folgende Art gewonnen. Die Stühle kürzlich in das Lazarett eingelieferter ruhrkranker Soldaten, welche nur aus Schleim und etwas Blut bestanden, wurden möglichst bald, oft sofort nach der Entleerung in das Laboratorium gebracht: Herausfischen einer Schleimflocke mit der Platinöse, ganz kurzes Abspülen in steriler, physiologischer Kochsalzlösung, dann in Sublimatlösung 1:10000, Verreiben auf drei Conradi-Drigalski-Platten mit einem rechtwinklig gebogenen Glasstabe. Nach 15- bis 20 stündigem Stehen im Brutschrank fanden sich fast ausschlieBlich makroskopisch unter sich gleichartige Kolonien vor.

Alle obigen Stämme erschienen blau, während viele andere, dort isolierte, meist wohl Coliarten, den Nährboden rot färbten.

Ich habe später im Institut für Infektionskrankheiten zu Berlin eine Nachprüfung auf Lackmus-Mannit-Agar rorgenommen, den mir Hr. Stabsarzt Dr. Kutscher freundlichst zur Verfügung stellte, wo nach 21 Stunden nur "Kolter" deutlich blau, die übrigen mit einem ganz leichten Stich ins Rötliche erschienen. Alle Typen waren unbeweglich.

Im folgenden ist das Verhalten der Stämme in einzelnen Nährböden und bei Gramscher Fārbung verzeichnet.

Zur Kontrolle diente ein Shiga-Stamm aus Tokio und ein KruseStamm aus Bonn.

\begin{tabular}{|c|c|c|c|c|c|c|c|c|c|c|}
\hline \multirow{2}{*}{ Typus } & \multirow{2}{*}{ 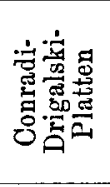 } & \multicolumn{2}{|c|}{ Lakmusmolke } & \multicolumn{3}{|c|}{ Hetsch-Kölbchen } & \multirow{2}{*}{ 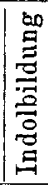 } & \multirow{2}{*}{ 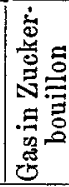 } & \multirow{2}{*}{ 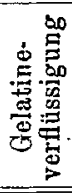 } & \multirow{2}{*}{ 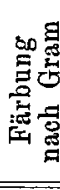 } \\
\hline & & $\begin{array}{c}\text { nach } \\
24-48 \text { Std. }\end{array}$ & $3 \stackrel{\text { nach }}{\text { Tagen }}$ & trübe & rot & $\begin{array}{l}\text { ver- } \\
\text { goren }\end{array}$ & & & & \\
\hline & blau & $\begin{array}{l}\text { wenig gerötet, } \\
\text { leicht getrübt }\end{array}$ & & - & - & - & - & - & - & - \\
\hline Kolter & & " & & - & - & - & - & - & - & 一 \\
\hline Beck & bläulich & $"$ & & + & + & - & - & - & - & - \\
\hline Müller & " & " & violett & + & + & - & - & - & - & -- \\
\hline Geisinger & , & $\begin{array}{l}\text { wenig gerötet, } \\
\text { stärkergetrübt }\end{array}$ & $\begin{array}{l}\text { stärker } \\
\text { gebläut }\end{array}$ & + & + & - & - & - & - & - \\
\hline
\end{tabular}

$\mathrm{Zu}$ Agglutinationsversuchen wurden folgende Sera verwendet:

1. Künstliches getrocknetes Shiga-Kruse-Serum von Hammeln aus lem Institut für Infektionskrankheiten in Berlin.

2. Kruse-Serum aus dem hygienischen Institut der Universität Bonn.

3. Shiga-Serum aus dem Institut für Infektionskrankheiten zu Tokio.

4. Polyvalentes Serum desgleichen.

5. Flexner-Serum aus Berlin.

6. Normales Hammelserum vom Schlachthof zu Kiel. 
Die Versuche wurden mit etwa 20 stündigen Kulturen angestellt, von denen eine Öse in $1 \mathrm{~cm}$ Serumverdünnung im Reagenzröhrchen verrieben wurde. Dann wurden die Röhrchen etwas hin und her bewegt, um die Agglutination der unbeweglichen Bazillen zu erleichtern (Martini und Lentz), und für 24 Stunden in den Brutschrank gestellt. Natürlich wurden stets Kontrollröhrchen mit Bazillenaufschwemmung in derselben Kochsalzlösung, wie sie zum Verdünnen des Serums benutzt wurde, gleichzeitig angesetzt.

Als positiv wurde nur makroskopisch oder mit ganz schwacher Lupe sichtbare Agglutination, durch Untersuchung im hängenden Tropfen kontrolliert, angesehen.

Niedrigere Serumverdünnungen als 1:50 wurden nicht vorgenommen.

Dabei ergaben sich, und zwar meist schon binnen einiger Stunden, zum Teil in $1 / 4$ Stunde, folgende Werte:

\begin{tabular}{c||c|c|c|c|c|c}
\hline \hline $\begin{array}{c}\text { Bazille n - } \\
\text { Ty p u s }\end{array}$ & $\begin{array}{c}\text { Shig.-Kruse } \\
\text { Berlin }\end{array}$ & $\begin{array}{c}\text { Krase } \\
\text { Bonn }\end{array}$ & $\begin{array}{c}\text { Shiga } \\
\text { Tokio }\end{array}$ & $\begin{array}{c}\text { Polyval. } \\
\text { Tokio }\end{array}$ & $\begin{array}{c}\text { Flexner } \\
\text { Berlin }\end{array}$ & $\begin{array}{c}\text { Hammel } \\
\text { normal }\end{array}$ \\
\hline \hline Bac. Shiga-Krase . & 2400 & 3000 & 1200 & 400 & - & - \\
" Kolter . . . & 2400 & 3000 & 1200 & 800 & 200 & 50 \\
" Beck .. . . & 800 & 400 & 200 & 400 & 100 & 50 \\
" Müller . . . & - & - & - & - & - & 50 \\
" Geisinger . . & - & - & - & 1200 & 50 & 100
\end{tabular}

Hiernach verhält sich der Stamm "Kolter" bezüglich der mittels des Bacillus Shiga-Kruse allein gewonnenen Seren genau so, wie die Originalstämme aus Tokio und Bonn.

Der Stamm „Beck" steht den Stämmen "Shiga“ und „Kruse" nahe.

Der Stamm ,Müller" scheint keine näheren Beziehungen zu den letzten beiden zu haben, ebensowenig "Geisinger". Der Stamm "Geisinger" wird auffallend hoch von dem polyvalenten Serum aus Tokio agglutiniert. Es scheint danach bei der Immunisierung der zur Serumgewinnung benutzten Tiere ein gleicher oder sehr ähnlicher Stamm verwendet zu sein.

Die drei letzterwähnten Stämme wachsen auf Agar üppiger als die Originalstämme und ,Kolter".

Sonst wurden in Tsingtau im Sommer 1904 selbst bei ganz frischeu Ruhrfällen, wo die Schleimflocken unmittelbar oder bald nach der Entleerung der Stühle mit oder ohne Abspülung in Sublimatlösung auf den Conradi-Drigalski-Platten verrieben wurden, nur stark rotfärbende Kolonien wahrgenommen, von denen einige aus unbeweglichen, teils plumpen, teils zarten Bazillen bestanden, andere wieder aus beweglichen. Fast alle bildeten Gas. 
Beobachtungen und Erfahrungen Über Ruhr in Ostasien. 33

Dieser Befund bei klinisch deutlich ausgesprochener Ruhr steht in auffallendem Gegensatz zu dem, was in früherer Zeit berichtet wurde.

Bei Dysenterieepidemien ist der Nachweis des Bacillus Shiga-Kruse oft sehr leicht gewesen, er hat sich hänfig fast in Reinkulturen auf den Platten vorgefunden.

Nach der neueren Literatur aber sind ähnliche Erfahrungen, wie in Tsingtau von mir, auch anderwärts gemacht worden, wie bereits bezüglich Japans erwähnt wurde.

Auch Eckert, der uns gelegentlich eines kurzen Aufenthalts in Tsingtau mitteilte, daß er die Shiga-Kruse- und Flexner-Bazillen in Tientsin sehr leicht gefunden habe, berichtete später, dab er im Sommer 1904 nur fünf Stämme gewann, von denen aber keiner den beiden vorgenannten glich.

Agglutinationsversuche mit dem Serum Rubrkranker wurden in Tsingtau nur bei einer geringen Anzahl von Fällen von mir angestellt, so daB darauf nicht weiter eingegangen sei.

Durch das oben Ausgeführte wird die schon von mehreren Autoren aufgestellte Behauptung unterstützt, daß die Ätiologie der nicht durch Amöben hervorgerufenen Ruhr keine einheitliche sei. Vieimehr kann wahrscheinlich eine ganze Anzahl verschiedener Bazillentypen die Krankheit hervorrufen.

Jedenfalls läBt der Umstand, daB auf Platten, die mit ganz frischem Matèrial akuter Ruhrfälle beschickt waren, in der Regel für den einzelnen Fall gleichartige Kolonien wuchsen, an einen gewissen Zusammenhang der gefundenen Bakterien mit der Krankheit denken. Da sich hier auch häufig Coliarten fast in Reinkultur vorfanden, so glaube ich, $\mathrm{da} B$ außer den Dysenterie- und Pseudodysenteriebazillen auch jene eine Ruhr, wenn auch leichtere, hervorzurufen imstande sind.

Bezüglich der Ätiologie der Amöbenruhr sind sich die meisten Forscher wohl darüber einig, daB die Amoeba histolytica ${ }^{1}$ in einem ursächlichen Zusammenhang zu den dysenterischen Darmveränderangen steht.

Es liegen eine Anzahl sorgfältigster Arbeiten vor, nach denen die Amöben durch eigne Kraft die intakte Mukosa durchdringen, um dann später in der Submukosa in ausgedehnterem MaBe ihre eigentliche zerstörende Tätigkeit zu entfalten.

Diese Beobachtungen stützen sich vielfach auf das Katzenexperiment. Bei der natürlichen Infektion des Menschen scheint aber doch nicht so bäufig diese Art des Eindringens der Protozoen zustande zu kommen.

1 In letzter Zeit ist eine neue Amöbe, Entamoeba tetragena, mit vierkernigen Cysten von Viereck and Hartmann beschrieben worden, welche bei Dysenterikern gefunden wurde.

Zeitsehr, f. Ilggione. LXI. 
Wenn man zwar auch hier und da in Schnitten menschlichen Darmes Amöben in den Drüsenschläuchen oder deren Nachbarschaft findet, so sieht man doch auch sehr oft einen ausgedehnten Zerfall des Darmepithels, ohne daB man auch nur eine Amöbe in den Schläuchen selbst oder deren Nachbarschaft entdecken kann. Man findet sie meist erst in der Submukosa. Amöben in völlig intakten Drüsen, wie sie Jürgens und Ruge nach Schnitten vom Katzendarm abgebildet haben, konnte ich trotz eifrigsten Suchens in Schnitten menschlichen Darmes nicht finden. Es scheint mir daher nicht unmöglich, daß bei der natürlichen Infektion des Menschen mit Amöbenruhr gewisse Bakterien (wie ja auch schon längst von anderer Seite angenommen wurde) oder andere, vielleicht chemische Schädlichkeiten die primäre Läsion in der Mukosa hervorrufen und dadurch erst den Amöben den Weg in die tieferen Schichten hinein öffnen, wo sie dann in hohem Grade gewebevernichtend auftreten.

$\mathrm{DaB}$ Mischinfektionen mit Amöben und Ruhrbazillen vorkommen, ist durch bakteriologische und mikroskopische Untersuchungen festgestellt.

Außerdem sprechen aber auch einige makroskopische Obduktionsbefunde dafür, wo von einer diphtheritischen Schleimhauterkrankung bei gleichzeitigem Amöbenbefunde die Rede ist.

Wir beobachteten in Tsingtau zwei solcher Fälle. In einem derselben wurden auf der wie mit Kleie bedeckt aussehenden Schleimhaut, wie sie für Bazillenruhr charakteristisch ist, bewegliche Amöben gefunden. In beiden wurden sie auch in den tieferen Schichten des Darmes nachgewiesen.

In der Leber dürften sie imstande sein, von vornherein allein eine Nekrose hervorzurufen, die in späteren Stadien freilich öfter, wie dann auch im Darm, durch Bakterien unterstützt werden mag.

Doflein und von Prowazeck, sowie Viereck halten ein Absonderungsprodukt der Ruhramöbe für das gewebszerstörende Element. Diese Absonderung scheint aber nicht dauernd stattzufinden, denn man sieht oft dichtgedrängte Haufen von Amöben, welche in völlig unversehrtes Gewebe eingebettet sind (siehe Taf. I, Fig. 2).

Die Erkennung der Amöben in den Stühlen ist, wenn sie beweglich sind, leicht. Die Bewegungen sind unter Umständen äußerst lebhaft, die Inhaltskörper werden schnell hin und her gerollt. Dann wieder sieht man die Amöben scheinbar mit einer gewissen Anstrengung ihr helles Ektoplasma zwischen dichtgedrängte rote Blutkörperchen hineinzwängen und diese auseinanderschieben.

Zuweilen sind einzelne Individuen mit Blutkörperchen vollgepfropft.

Schwerer ist es, die Ruhramöben in ruhendem Zustande zu identifizieren. Aber auch hier werden die scharfen Konturen, der stark licht- 
brechende Ektoplasmasaum die Gebilde dem geübten Beobachter kenntlich machen, auch wenn sie keine roten Blutkörperchen enthalten.

Der weniger Geübte freilich ist bei unbeweglichen Amöben manchen Täuschungen ausgesetzt. Gequollene, in Degeneration befindliche Epithelien, in denen Fetttröpfchen für Vakuolen gehalten werden, auch gequollene Leukozyten können Amöben vortäuschen (siehe Taf. III, Fig. $3 b$ und $c$ ).

Noch mehr Irrtümern ist man bei gefärbten Stuhlausstrichen aus. gesetzt. Es haben sich hierdurch schon verschiedene, auch geübtere Untersucher täuschen lassen.

Im allgemeinen muß daher der Grundsatz gelten, daß von Amöben in den Stühlen nur dann gesprochen werden darf, wenn man sie in beweglichem Zustande gesehen hat.

Bezūglich der Unterscheidung der Dysenterieamöben von anderen sei auf die Arbeiten von Schaudinn und Viereck verwiesen.

In Schnitten erscheinen die Amöben (Amoebae histolyticae) viel kleiner als im Stuhl. Das Ektoplasma ist gewöhnlich nicht erkennbar, der Kern jedoch, im Gegensatz zum lebenden Zustande, oft gut zu sehen.

Zur Schnittfärbung bat sich mir außer der gebräuchlichen HämatoxylinEosin-Färbung die Weigertsche mit Eisen-Hämatoxylin und Nachfärbung mit Pikrokarmin gut bewährt. Die Amöben erscheinen hierbei je nach dem Alter der Eisen-Hämatoxylin-Lösung smaragdgrün oder grau und heben sich deutlich von der umgebenden rosagefärbten Submukosa, welche ja meist zunächst in Frage kommt, ab. Die Darmepithelien und Leukozyten erscheinen stets olivgrün (siehe Taf. I, Fig. 2).

Auch die Färbung in stark verdünnter Giemsalösung mit Zusatz von Essigsäure (24 Stunden lang) gibt gute Bilder: Amöben blau, Submukosa rosa (siehe Taf. VIII).

\section{Pathologische Anatomie. ${ }^{1}$}

Die Untersuchungen von Virchow, Kartulis, Kelsch und Kiener, Councilman und Lafleur, Kruse und Pasquale, Jürgens, Rogers und Haasler, die zum Teil mit vorzüglichen Abbildungen veröffentlicht wurden, haben die pathologiseh-anatomischen Verhältnisse beider Ruhrarten zum größten Teil geklärt.

Das makroskopische Aussehen des Ruhrdarms ist ziemlich allgemein bekannt. Unsere ostasiatischen Beobachtungen weichen nicht von denen Anderer ab.

${ }^{1}$ Hrn. Geheimrat Prof. Dr. Heller bin ich zu großem Danke verpflichtet für die Erlaubnis, daß ich im Pathologischen Institute der Universität Kiel meine aus Ostasien mitgebrachten Ruhrdarmstücke verarbeiten konnte; Hrn. Prof. Dr. Döhle für Ratschläge bei Anfertignng der Präparate, desgleichen Hrn. Dr. Wilke. 
Mikroskopisch findet man im Beginn der Bazillenruhr eine starke Rundzellenanhāufung in der Mukosa, deren Drüsenschlāuche mehr oder weniger zerfallen sind (siehe Taf. IV). Die verdickte Submukosa ist, besonders in der Nähe der Schleimhaut, oft von einem Netz erweiterter Kapillaren durchsetzt, auch finden sich ausgedehnte Blutextravasate, beides in meinen Präparaten in auffallenderem Maße, als bei der Amöbenruhr.

Bei der Amöbenruhr erscheint die Schleimhaut mikroskopisch zum Teil unversehrt, zum Teil mehr oder weniger im Zerfall begriffen. Wie aber schon erwähnt, sieht man am Menschendarm in der Drüsenschicht selbst nur verhältnismäßig wenig Amöben, und zwar innerhalb der Schläuche noch weniger als im interglandulären Gewebe.

Dagegen sind sie in der Submukosa zahlreich, liegen öfter in Nestern so dichtgedrängt zusammen, daB sie in gehärtetem Zustande eine fazettierte Form angenommen haben. Häufig findet man sie massenhaft in der Nähe der Venen, in welche sie auch öfter eindringen (siehe Taf.VIII). In Arterien sah ich sie nie, dagegen oft in LymphgefäBen, an deren Wand sie hafteten.

Die Rundzellenansammlung in der Nähe der Amöben ist meist spärlich, die Kapillarektasien und Ekchymosen sind nicht so auffallend wie bei der Bazillenruhr.

Die Submukosa ist von Bindegewebszŭgen durchwuchert (siehe Taf. VII, wo das Bindegewebe rot und ödematös erscheint) und erheblich verbreitert. Hier und da hat man den Eindruck, daB die Amöben von der Submucosa aus in die Mukosa eindringen (siehe Taf. VII), wo sie dann das Epithel der Drüsenschläuche in die Höhe heben und zusammenschieben können, ohne es aber zu zerstören.

Die Bindegewebsmaschen der Submukosa quellen allmählich auf, so daB sich dann das für Amöbenruhr charakteristische, schon von Councilman und Lafleur so gut abgebildete hyaline Netz entwickelt. Auf Taf. VII ist diese allmähliche Netzbildung sichtbar. Unten erkennt man noch die Bindegewebszüge, welche das Karmin angenommen und festgehalten haben, während oben die gequollenen, nur schwach gelblich gefärbten hyalinen Netzmaschen sichtbar sind, welche nicht nur, wie Councilman und Lafleur schreiben, Leukozyten, sondern auch Amöben enthalten.

Die Weigertsche Fibrinfärbung des Netzes fällt negativ aus.

Von der Submukosa aus dringen die Amöben in die Muskularis ein, und zwar folgen sie hier oft den Bindegewebssepten, bis sie schlieBlich mit oder ohne gänzliche Zerstörung der Muskelschicht die Serosa erreichen.

Letztere ist öfters ebenfalls ganz enorm ödematös verdickt. 


\section{Beobachtungen und Erfahrungen Über Ruhr in Ostasten. 37}

In den Mesenterialdrūsen habe ich Amöben nicht entdecken können.

Bei chronischer Ruhr können die Drüsenschläuche zystisch entarten und zu polypösen Wucherungen auswachsen (siehe Taf. VI, Fig. 1).

$$
\text { Epidemiologie. }
$$

Die Bazillenruhr hat auch in Ostasien einen epidemischen Charakter. Wie in Europa, so erscheint sie auch hier hauptsächlich in den wärmsten Monaten und zwar beim Utbergang von der Regen- zur Trockenzeit. Im Spätherbst tritt sie dann seltener auf und verschwindet im Winter noch mehr. Sie zeigt sich dann nur in chronischen Fällen, um im nächsten Sommer wieder neu aufzuflackern.

Die Untersuchungen der letzten Jahre machen es wahrscheinlich, $\mathrm{dak}$ die Utbertragungen von einem Sommer zum andern durch den Menschen selbst vermittelt werden. Man hat im Darminhalte klinisch Gesunder Ruhrbazillen nachgewiesen (Conradi u. a.), und dab die chronisch Kranken sie in ihrem Darm noch beherbergen können, steht fest.

In einzelnen Gegenden Ostasiens hat sich in den letzten Jahren eine auffallende Abnahme der Ruhr, und zwar wohl der bazillären, gezeigt. Shiga hat kürzlich darauf hingewiesen, daB in Japan die Ruhr von Süden nach Norden gezogen ist, daB dann eine Remission, und nach etwa 10 Jahren ein erneutes Umsichgreifen der Seuche bemerkbar wurde. Er erklärt diese Remission mit einer natürlichen Immunitāt der verschiedenen Landstriche, welche jahrelang vorgehalten habe (ähnlich äußert sich auch Conradi bezüglich der Gegend von Metz). Shiga teilt auch mit, daB, wenn die Krankheit in einem Jahre ein Dorf heimgesucht hätte, dieses im nächsten mit großer Wabrscheinlichkeit verschont bliebe.

In Nordchina ist die Bazillenruhr augenblicklich ebenfalls im Rückgange. Während noch vor wenigen Jahren dort viel schwere Fälle beobachtet wurden, sind diese jetzt seltener.

Die Hygiene allein kann als schützendes Mittel wohl für die Aufenthaltsorte der deutschen Truppen in Frage kommen, nicht aber für die japanischen Dorfbewohner, bei denen sich in den letzten Jahren kaum so außerordentlich viel geändert haben dürfte.

Eine Immunität ferner kann wohl für die Bewohner Japans, nicht aber für die deutschen in China stationierten Truppen in Betracht kommen, da die Angehörigen derselben meist nie früher in Ostasien waren, sondern direkt aus der Heimat dorthin gelangt sind. Vielleicht sind also die Ursachen fǘr den Rückgang der Bazillenruhr in Japan die Immunität der Bevölkerung, in den europäisch bewohnten Teilen Nordchinas die besseren gesundheitlichen Verhältnisse, unter denen die Truppen jetzt dort leben, vielleicht sind auch noch andere Ursachen wirksam. 
Die Amöbenruhr scheint nach Vierecks neueren Mitteilungen ebenfalls in den wärmeren Monaten häufiger aufzutreten. Auch die wenigen von uns in Tsingtau beobachteten Fälle sprechen im allgemeinen hierfür.

$$
\text { Prophylaxe. }
$$

Die Prophylaxe ergibt sich zum Teil schon aus den früheren Ausführungen unter "Infektionsbedingungen".

Bei Bazillenruhr wird man vor allem sein Augenmerk auf die ersten Fälle des Sommers oder einer Epidemie zu richten haben, die sich vielleicht zunächst nur als Darmkatarrhe zeigen. Man wird die Kranken isolieren, ihre Entleerungen unschädlich machen und wenn möglich, im Laboratorium das Wesen des Krankheitserregers festzustellen suchen.

Bei Menschenansammlungen, wie sie in Feldzügen und an Bord der Schiffe vorhanden sind, muß der Arzt natürlich ein besonders wachsames Auge haben. Die Aborte müssen sorgfältig überwacht, der Inhalt nach Möglichkeit kontrolliert werden, ob durchfällige oder gar blutig-schleimige Entleerungen dort stattgefunden haben. Auch müssen die Mannschaften dazu angehalten werden, ihre Stühle selbst zu beobachten und sich nach Benutzung der Klosetts stets die Hände zu waschen.

Speisen und Getränke müssen überwacht werden. Grŭne Salate, Radieschen usw., ferner von Eingeborenen feilgebotene Backwaren und SüBigkeiten sind ganz zu verbieten, Obst nur gründlich gewaschen und geschält zu gestatten. Vor Selterswasser und Limonaden aus unsicherer Quelle ist zu warnen. Das Wasser darf in Ruhrgegenden, falls es nicht aus einer ganz einwandfreien Leitung stammt and in einwandfreien Gefäßen geschöpft wird, nur abgekocht, am besten mit Zusatz einer Sāure, genossen werden. Kann es aus irgend einem Grunde nicht genügend abgekühlt werden, so verabreiche man Tee, der auch im warmen Zustande gut durstlöschend ist und durch seinen Tanningehalt vielleicht auch einer Infektion entgegenwirkt. ${ }^{1}$ Geeiste Getränke sind unter Umständen sehr schädlich, da sie Magendarmkatarrhe hervorrufen und so zur Ruhr disponieren können.

Ferner müssen für Darmkranke besondere Klosetts eingeräumt werden, die zweckmäßig gegen Fliegen geschützt sind.

In Ansehung der Staubstürme müssen EBwaren, an denen leicht Staub haften kann, verdeckt aufbewahrt werden. Auch wird unter Umständen, z. B. auf Expeditionen, das Tragen gut sitzender (s. o.) Leibbinden zu empfehlen bzw. anzuordnen sein.

${ }^{1}$ In Tsingtau standen in allen Kasernen groBe Eisenbehälter mit Tee oder abgekochtem Wasser den Mannschaften zur Verfügung. 
Beobachtungen und Erfahrungen Über RuHr in Ostasten. 39

Auf die Eingeborenen wird in der Regel ein EinfluB in hygienischer Beziehung ohne Zwang nicht möglich sein. Von den Voreltern überkommene, oft geradezu geheiligte Lebensgewohnheiten, zum Teil Aberglauben, zum Teil Gleichgültigkeit, setzen allen hygienischen Ratschlägen einen schwer za überwindenden Widerstand entgegen. Erinnert sei nur an die religiösen Übungen der Hindus. ${ }^{1}$

Die Engländer suchen in Indien dadurch Waidel zu schaffen, daß sie Eingeborene in europäischer Weise zu Ärzten ausbilden, um so die abendländischen Begriffe von Hygiene auch in das indische Volk hineinzutragen.

Was übrigens eine zielbewußte Bekämpfung der Ruhr erreichen kann, hat u. a. Wolffhügel gezeigt, der während der Chinawirren bei seinem Bataillon durch streng durchgeführte hygienische MaBnahmen (tägliche Kontrolle der Lagerlatrinen, Desinfizieren derselben, Ausgeben von nur abgekochtem Trink- und Waschwasser) so gute Erfolge hatte, daB in 9 Monaten bei 879 Mann nur 23 Ruhrkranke zugingen und keiner starb.

${ }^{1}$ Böse, Eine Reise nach Sumatra und Britisch-Indien. Deutsche med. Wochenschrift. 1906. 


\section{Literatar-Verzeichnis.}

1. Albu, Sporad. einh. Rahr. Zeitschrift für klin. Medizin. Bd. LVI.

2. de Blasi, Vergl. Studien einiger Stämme des Bacterium dysentericum. Centralblatt für Bakteriologie. Bd. XXXVI.

3. Boas, Über einen Fall von operativ behandelter Colitis ulcerosa. Deutsche med. Wochenschrift. 1903. Nr. 11.

4. Bericht über 70. Annual Meeting of the British Med. Ass. held at Manchester. 29. Juli bis 1. August 1902. Section of trop. diseases.

5. Bertanelli, Die Amöben und die Amöbenruhr. Wiener klin. Rundschan. 1905. Nr. 23.

6. Berghing, Über Serumtherapie bei Dysenterie. Annali d'ig. sper. Vol.IX. Fasc. 4. Zit. aus Centralblatt für Bakteriologie. Bd. XXX.

7. Bofinger, Über die in Lüderitzbucht beobachteten Ruhrerkrankungen and ihre bakteriol. Untersuchang. Archiv für Sch. u. Tropenhygiene. 1906.

8. Bow man, Dysentery in the Philippines. Journ. of trop. med. 1901. Vol. IV. Zit. aus Centralblatt für Balkteriologie. Bd. XXXI. Ref.

9. Bornträger, Die Ruhrepidemie im Regierungsbezirk Danzig 1895/96. Diese Zeitschrift. Bd. XXVII.

10. Derselbe, Die Wege der Übertragung. bei Typhus und Rahr. Gesundheit. Nr. 11 bis 15.

11. Breitenstein, $2 l$ Jahre in Indien.

12. v. Brero, Einiges über die Therapie der katarrhal. Dysenterie in den Tropen. Archiv für Sch.- u. Tropenhygiene. 1902.

13. Bronton, A clinical lecture on Dysentery and Intestinal Eaemorrhage. The Lancet. Juli 1903.

14. Buchanan, Siehe Nr. 4.

15. Derselbe, The saline treatment of Dysentery. Archiv f. Sch.- u. Tropenhygiene. 1899.

16. Derselbe, The prevention and treatment of Dysentery in institutions in the tropics. Brit. med. Journal. 20. Sept. 1902.

17. Dersel be, Discussion on Dysentery. The Journ. of trop. med. 15. Ang. 1902.

18. Bunthing, Haematogenous amoebic abscess of the lung. Archiv f. Sch.u. Tropenhygiene. 1906.

19. Buttersack, Beobachtungen n. Untersuchangen über die Ruhr. Veröffentl. a. d. Gebiete d. Militär-Sanitätswesens. 1902.

20. Calmette, Etude expérimentale de la dysenterie. Arch. de Méd. T. LIX.

21. Derselbe, Note sur la présence du bacille pyoc. dans le sang et dans l'intestin de dysenteriques en Cochinchine. Ebenda. T. LVII. 
Beobachtongen und Erfahruateen Über Rutr in Ostasien. 41

22. Castellani, Dysentery in Ceylon. The Journ. of the Ceylon Branch of the Brit. Med. Assoc. 1904.

23. Ciechanowski nnd Nowak, Zur Ätiologie der Dysenterie. Centralblatt fiir Bakteriologie. Bd. XXIII.

24. Celli, Etiologia della disenteria etc. Ann. d’igiene sper. 1906. Zit. aus Centralblatt für Bakteriologie. Bd. XXI.

25. Celli und Fiocca, Über die Ätiologie der Dysenterie. Centralblatt für Balcteriologie. Bd. XVII.

26. Celli und Valenti, Nochmals über die Ätiologie der Dysenterie. Ebenda. Bd. XXV.

27. Councilman u. Lafleur, Amoebic Dysentery. The John Hopkins Hospital Reports. 1891.

28. Conradi, Über eine-Kontaktepidemie von Ruhr i. d. Umgegend von Metz. Festschrift z. 60. Geburtstage v. R. Koch.

29. Craig, Observations upon the amoebae coli and their staining reactions. Med. News. 1902. Zit. aus Centralhlatt für Balcteriologie. Bd. XXXI.

30. Curl, De la valeur relative de la caecostimie et de l'appendicostomie dans le traitement de la dysenterie amibienne par les irrigations du colon. La Sem. méd. 1906. Nr. 33.

31. Cybulski, Ätiologie der Dysenterie. Zit. ans Deutsche med. Wochenschrift. 1905. Nr. 21.

32. Desai, The rational treatment of Dysentery. Brit. med. Journ. 1903.

33. Dock, Amebic Dysentery in Michigan. Journ. of the Am. med. ass. 13. Sept. 1902. Zit. aus Archiv f. Sch.- u. Tropenhygiene. Hft. 7.

34. Doflein und v. Prowazeck, Die pathogenen Protozoen. Handb. d. path. Mikroorganismen von Kolle-Wassermann.

35. Dombrowsky, Zur Biologie der Dysenteriebazillen. Archiv für Hygiene. 1903. Bd. XLVII.

36. Dörr, Beobachtungen über die bazilläre Dysenterie. Centralbl.f. Balkteriol. Bd: XXXII.

37. Dopter, Über eine in Frankreich vorgekommene Übertragung von Amöbendysenterie. Acad. de méd. 2. Nov. 1904. Zit. aus Deutsche med. Woch. 1906. Nr. 33.

38. Duncan, A discussion on dysentery. Brit. med. Journ. 20. Sept. 1902.

39. Dugat, Note on the use of the Root Bark of Ailantus in Dysentery. Report des chin. Seezolls. 1875.

40. Dudgeon, Report on the health of Peking. Seezollrapporte. 1874.

41. Dutroulan, Traité des mal. des européens dans les pays chauds.

42. Eckert, Bakteriol. Untersuchungen über die Rahr in Nordehina. Deutsche militär-ärztl. Zeitschr. 1906.

43. Erni, Die Krankenfürsorge in Niederl.-Indien. Archiv f. Sch.- u. Tropenhygiene. 1899.

44. Escherich und Pfaundler, Bact. coli. Handb. d. path. Mikroorganismen von Kolle-Wassermann.

45. Faitschnie, Dysentery, its cansation, varieties, and treatment on Active service. Brit. med. Journ. 12. Aug. 1905.

46. Ficker, Typhus u Fliegen. Centralblatt für Bakteriologie. 1903. Nr. 21.

47. Fiebig, Einfluß des Alkohols auf den Europäer in den Tropen. Archiv $f$. Sch.- $u$. Tropenhygiene. 1903.

48. Flexner, The Etiologie of Tropical Dysentery. Centralbl. f. Bakt. Bd. XXVIII. 
49. Flexner, A comparative study of dysenteric bacilli. Centralbl. f. Bafteriol. Bd. XXX.

50. Frost und Whitman. Die Lebensf. des Bac. dysent. Shiga. Verh. der 6. Jahresvers. d. Ges. Amer. Bakteriologen. Centralbl. f. Bakt. Bd. XI u. XIV. Ref.

51. Gabrischewsky, Über die Technik der Immunisierung von Pferden gegen Dysenterie. Deutsche med. Wochenschrift. 1904. Nr. 19.

52. Gaffky, Eine Hausepidemie von fieberh. Brechdurchfall. Festschrift zum 60. Geburtstage R. Kochs.

53. Gay a. Duval, Acnte dysentery associated with the two types of Bacillus dysenteriae Shiga. University of Pensylvania. Med. Bulletin. Juli-August 1903.

54. Gneftos, Ein dys. LeberabszeB bei einem 6 jähr. Kinde. Deutsche med. Wochenschrift. Bd. XXXII.

55. Goebel, Über Lieberabszesse. Med. Sekt. der schles. Ges. f. vaterl. Kultur. Breslau 28. Juli 1905. Berliner kelin. Woch. 1905. Nr. 37.

56. Derselbe, Über Leberabszesse. Mitteilungen aus den Grenzgebieten für Medizin u. Chimurgie. Bd. XV.

57. Derselbe, Ein Fall von Dysenterie, in China aquiriert, usw. Allgem. Med. Central-Zeitung. 1906. Nr. 11.

58. Herhold, Über die bei der 2. Brigade des Ostas. Exp.-Korps vorzugsweise vorgekommenen Krankheiten mit Bezug anf Klima und Boden der Provinz Petschili in China. Deutsche militär-ärztl. Zeitschr. 1901. Hft. 12.

59. Herz, Der Sanitätsdienst der engl. Armee im Kriege gegen die Buren.

60. Hetsch, Weiteres zur kulturellen Differenzierung der Ruhrbazillen gegenüber ruhrähnl. Bakterien. Centralblatt für Bakteriologie. 1903. Nr. 6.

61. Haasler, Über Folgeerkrankungen der Ruhr. Deutsche med. Wochenschrift. 1902. Nr. 2.

62. Hamilton, The fly as a carrier of typhoid. Journ. of the amer. med. ass. 1903. Zit. aus Centralblatt für Bakteriologie. 1904. Nr. 4.

63. Hillebrecht, Über ruhrartige Erkrankungen in Deutsch-Südwestafrika. Archiv f. Sch.- u Tropenhygiene. 1905. Nr.9.

64. Hippokrates Sämtliche Werke, übersetzt von Fuchs,

65. Hirsch, Handbuch der hist.geograph. Pathologie.

66. Hoppe-Seyler, Dysenterie and Amöbenenteritis. Deutsche Rlinit am Eingang des XX. Jahrh. Bd. II.

67. Derselbe, Über Erkrankung des Wurmfortsatzes bei chron. Amöbenenteritis. Münchener med. Wochenschrift. 1904. Nr. 15.

68. Janowski; Zur Ätiologie der Dysenterie. Centralblatt für Bakteriologie. Bd. XXI.

69. Jür gens, Zur Kenntnis der Darmamöben und der Amöbenenteritis. Deröff. a. d. Geb. d. Militär-Sanitätswesens.

70. Derselbe, Zur Atiologie der Rahr. Deutsche med. Wochenschr. 1903. Nr. 46.

71. Derselbe, Über Amöbenenteritis und jhre Beziehungen zur epidem. Ruhr. Berliner klin. Wochenschrift. 1906. Nr. 50.

72. Kartulis, Zur Ätiologie der Dysenterie in Ägypten. Virchows Archiv. Bd. CV.

73. Derselbe, Über Tropen-Leberabszesse. Centralbl. f. Bakter. 1890. Bd. VII

74. Derselbe, Über weitere Verbreitungsgeb. der Dysenterieamöben. Ėbenda. 1890. Bd. VII

75. - Derselbe, Einiges üb. d. Pathogenese der Dys.-Amöb. Ełenda. 1891. Bd. IX. 


\section{Beobachtungen und Erfahrungen Über RuHR in Ostasten. 43}

76. Kartulis, Contribution à l'étude étiologique de la dysenterie. Compt.rend. de la Soc. de Biol. 2. Febr. 1893.

77. Kelsch u. Kiener, Traité des maladies des pays chauds. 1889.

78. Korentschewsky, Zur Frage der mandschur. Dysenterie. Autoreferat im Centralblatt $f$. Bakteriologie. Bd. XXXVII. Nr. 7.

79. K rämer, Die Leberkongestion, ihre Beseitigung und Unterscheidung vom LeberabszeB. Archiv f. Sch.= u. Tropenhygiene. 1906.

80. Kraus and Dörr, Über exp. Therapie der Dysenterie. Vortrag. Zit. aus Therap. Miconatshefte. 1906.

81. Dieselben, Antitoxische Therapie der baz. Dysenterie. Diese Zeitschr. 1906.

82. Kruse und Pasquale, Eine Exp. n. Ägypten zum Studium d. Dysenterie und des Leberabszesses. Deutsche med. Wochenschrift. 1903. Nr. 15/16.

83. Dieselben, Untersuchangen über Dysenterie und Leberabszesse. Diese Zeitschrift. Bd. XVI.

84. Kruse, Die Ruhrgefahr in Deutschland usw. Centralblatt für allgemeine Gesundheitspflege. 1906. Nr. 5/6.

85. Derselbe, Weitere Untersuchungen über die Ruhr and die Ruhrbazillen. Deutsche med. Wochenschrift. 1903. Nr. 23/24.

86. Derselbe, Die Serumtherapie bei Dysenterie. Ebenda. 1903. Nr. 1 u. 3.

87. Derselbe, Neue Untersuchungen üb. die Ruhr. Ebenda. 1907. Nr. 8 n. 9.

88. Le Dantec, Traitement de la Dys. des pays chands. Arch. de Méd. nav. T. LIV.

89. Luce u. Meinecke, Bericht über das Marine-Lazarettschiff "Savoia“ ușw. Archiv f. Sch.- u. Tropenhygiene. 1903.

90. Lentz, Weitere Beiträge zur Differenzierung der Shiga-Kruseschen und Flexnerschen Bazillen. Diese Zeitschrift. 1903. Bd. XLIII.

91. Derselbe, Dysenterie. Handb. d. pathog. Mikr. v. Kolle-Wassermann.

92. Lösch, Massenhafte Entwicklung von Amöben im Dickdarm. Virchows Archiv. Bd. LXV.

93. Lü dke, Beobachtungen üb. die bazilläre Dysenterie im Stadtkreise Barmen

1904 and 1905. Deutsche med. Wochenschrift. 1906. Nr. 5-7.

94. Derselbe, Unters. üb. d. baz. Dysenterie. Centralbl.f. Bakteriol. Bd. XI.

95. Mac Callum, Trop. Leberkrankheiten. Handb. d. Tropenkr. von Mense.

96. Macleod, Some Difficulties in Dealing with Liverabscess, and How to obviate them. Journ. of trop. Medicine. Nov. 1900.

97. Derselbe, Tropical Abscess etc. The Lancet. 26. Okt. 1895.

98. Maggiora, Einige mikroskop. a. bakteriol. Beobachtungen während einer Epidemie dys. Dickdarmentzündung. Centralblatt für Bakteriologie. Bd. XI.

99. Manson, On the operative treatment of hepatitis and hepatic abscess. Seezollrapporte. 1883.

100. Martini und Lentz, Über die Differenziernng der Ruhrbazillen mittels Agglutination. Diese Zeitschrift. Bd. XLI.

101. Marx, Die expr. Diagnose, Serumtherapie und Prophylaxe der Infektionskrankheiten.

102. Mason, Bacillery dysentery. The Journ. of the Amer. med. ass. 25. Juli und 26. Angust 1903. Centralblatt für Baleteriologie. 1904. Nr. 14/15. Ref. 103. Derselbe, Bacillery dysentery. Compt. rend. de la soc. de biol. 1903.

T. LV. Nr. 16. Zit. Centralblatt für Baleteriologie. 1904. Nr. 14/15. Ref.

104. Massiutin, Üb. d. Amöb. als Parasiten des Dickdarms. Zit. Ebenda. Bd.VI. 
105. Mayer, Untersuchungen von Wasserläufen in China. Centralblatt für Bakteriologie. 1903 . Nr. 6.

106. Meyer, Uber chron. Dysenterie and ihre Behandlung. Deutsche med. Wochenschrift. 1906. Nr. 33.

107. Moulinier, Hépatite suppurée. Arch. de méd. nav. T. LXXVILL

108. Monreul and Rieux, Du Bacille dysenterique, sa constance dans la dysenterie, ses charactères differentielles. Compt. rend. hebd. T. LIII. Zit. aus Centralblatt für Bakteriologie. Bd. XXXII. Ref.

109. Momose, Über Dysenterie in Korea. Centr. f. Bakt. 1906. Nr.23/25. Ref.

110. Morgenroth and Bassenge, Bericht über die im bakteriol. und chem. Laboratorinm zu Tientsin in der Zeit v. 1.X. 00 bis 1.III. 01 ansgeführten Arbeiten. Deutsche militär-ärrtl. Zeitschrift.

111. Morgen roth und Eckert, II. Bericht aus dem bakteriol. n. chem. Laboratorium des ostas. Exp.-Korps and der Besatzungsbrigade. Ebenda. 1902. Nr.2.

112. Morgenroth, Über Ruhruntersuchungen in China, im besonderen über die Bakterienarten, die bei chin. Ruhr gefunden und durch Blatserum agglatiniert warden. Archiv f. Sch.- u. Tropenhygiene. 1904.

113. Musgrave, Treatment of intestinal amebiasis. Dep. of the Inter.

114. Derselbe, Amebiasis: Its association etc. The Philippine Journal of Science. 1906. Nr. 5.

115. Musgrave n. Clegg, Amebas: Their Caltivation and Etiologie. Significance Departm. of the Interior.

116. Müller, Über den bakteriol. Befund bei einer Dysenterieepidemie in SüdSteiermark. Centralblatt für Bakteriologie. Bd. XXXI.

117. Nenninger, Obermarineärztliche Prüfungsarbeit.

118. Derselbe, Über Herzerkrankungen bei Ruhr. Archiv f. Seh.* u. Tropenhygiene. Bd. VII.

119. Nocht, Vorlesungen für Schiffsärzte.

120. Ono, Ruhr in der Mandschurei. Centralbl. f. Bakt. 1906. Nr. 23/25. Ref.

121. Paranchos, Contribution à l'étude de la dysenterie dans les pays chauds. Progrès méd.

122. Pfuhl, Vergl. Ontersuchungen über die Haltbarkeit der Ruhr-u. Typhusbazillen außerhalb des menschl. Körpers.

123. Derselbe, Beobachtangen nad Untersuchungen über Ruhr. Veröffentl.a. d. Gebiete des Militär-Sanitätswesens.

124. A. Plehn, Zur Dysenteriebehandlung. Deutsche. med. Woch. Ed. I. Nr.39. 125. Quincke und Roos, Über Amöben-Enteritis. Berliner klin. Wochenschr. 1893. Nr. 45.

126. Quincke, Über Protozoen-Enteritis. Ebenda. 1899. Nr. 46 a. 47.

127. Rasch, Über Salol bei Dysenterie. Deutsche med. Wochenschr. 1893. Nr.17.

128. Derselbe, Anwendung der Baelfrucht bei Dysenterie. Archiv f. Sch.- $u$. Tropenhygiene. 1899.

129. Rantenberg, Zur Bakteriologie der Ruhr. Centralbl. f. Bakt. 1904. Nr.3.

130. Recoules, Note sur l'occupation de Koang-Tschéon-Wan. Areh. de méd. nav. T. LXXIV.

131. Rogers, Further work on Amoebic Dysentery in India. The Brit. Med. Journ. 6. Juni 1903. Vol. II.

132. Derselbe, Blood Counts in Acute Hepatitis etc. The Lancet. 1905. Nr. 9. 
133. Rosenthal, Zur Ätiologio der Dysenterie. Deutsche med. Wochenschrift. 1903. Nr. 6.

134. Derselbe, Über Serumtherapie bei Dysenterie. Centralbl. f. Bakteriologie. 1904. Nr. 16/17. Ref.

135. Derselbe, Das Dysenterietoxin. Deutsche med. Wochenschrift. 1904. Nr.7.

136. Derselbe, Ein nenes Dysenterieserum u. seine Anwendang b. d. Dysenterie.

Ebenda. 1904. Nr. 19.

137. Ruge, Ein Wort zur Behandlung frischer Fälle tropischer Dysenterie mit Ipekakuanha. Ebenda. 1901. Nr. 14.

138. Derselbe, Zur Ätiologie and Verbreitangsweise der Dysenterie in den

Tropen. Vortrag, gehalten a. d. 75. Versammlung deutscher Naturforscher a. Arzte. Archiv f. Sch.- u. Tropenhygiene. 1903.

139. Derselbe, Zur Átiologie usw. Rlin.-therap. Wochenschrift. 1903. Nr. 46/47.

140. Derselbe, Bazillenruhr. Menses Handbuch für Tropenkrankheiten.

141. Derselbe, Amöbenruhr. Ebenda.

142. Sachs, Über die Hepatitis der heißen Länder asw. Archiv für klin. Chirurgie. 1876.

143. Sanitätsbericht der Marine.

144. Sanitätsbericht des ostasiatischen Expeditionskorps.

145. Sanitätsherichte der ostasiatischen Besatzungsbrigade.

146. Schaudinn, Untersuchungen über die Fortpflanzung einiger Rhizopoden. Arbeiten aus dem Raiserl. Gesundheitsamte. 1903. Bd. XIX.

147. Seheube, Krankheiten der warmen Länder.

148. Schlayer, LeberabszeB im Rückfall. Münchener med. Wochenschr. 1904. Nr. 8.

149. Schüle, Über die Sondierung und Radiographie des Dickdarmes. Verein Ereiburger Ärzte. 29. Januar 1904.

150. Sheldon Amos, A note on the treatment of catarrhal and gangrenous Dysentery. The Lancet. Angust 1906.

151. Shiga, Über den Dysenteriebacillus (Bacterium dysenteriae). Centralblatt für Balcteriologie. Bd. XXIV.

152. Derselbe, Üb. d. Erreger d. Dysenterie in Japas usw. Ebenda. Bd. XXIII.

153. Derselbe, Studien über die epidem. Dysenterie in Japan usw. Deutsche med. Wochenschrift. Bd. I. Nr. 43-45.

154. Derselbe, Über Versuche zur Schutzimpfung gegen die Ruhr. Ebenda. Bd. III. Nr. 18.

155. Derselbe, Observation on the Epidemiologie of dysentery in Japan. The Philippine Journal of Science. 1906. Nr. 5.

156. Sinnhuber, Ein Fall ron medizin. Kalomelvergiftung. Therapeutische Monatshefte. 1906.

157. Statistique médicale des Troupes coloniales en France aux colonies pendant l'année 1903.

158. Stephan, Vorstellung eines durch Kolostomie geheilten Falles hartnäckiger Dysenterie. Berliner klin. Wochenschrift. 1906. Nr. 1.

159. Sternberg, Über Klystiere und Irrigationen. Deutsche med. Wochenschr. 1906. Nr. 6 n. 7 .

160. Strassburger, Beiträge zur Behandlung der Ruhr mit Rad. Ipec. Münchener med. Wochenschrift. 1902. Nr. 36.

161. Strong, Fatal intestinal haemorrhage etc. Lancet. 1906. March. 
162. Sutherland, Einiges über das Altagsleben und die Volksmedizin unter en Bauern Britisch-Indiens. Münchener med. Wochenschrift. 1906. Nr. 12.

163. Thomson, Rapporte des chin. Seezolls. 1900.

164. Todd, On a dysentery antitoxin. Brit. med. Journ. 1903. Zit. Centralblatt für Balcteriologie. 1904. Nr. $10 / 11$.

165. Derselbe, On a dysentery toxin and antitoxin. Journ. of Hygiene. 1904. Zit. Centralblatt für Bakteriologie. Bd. XXXVII. Nr. 7-10.

166. Vi ereck, Über Amöbendysenterie. Med. Klin. 1906. Nr. 41.

167. Derselbe, Studien über die in den Tropen erworbene Dysenterie. Archiv f. Sch.- u. Tropenhygiene. Beiheft I.

168. Vaillard u. Vopter, La dysenterie épidémique. Ann. de l'Inst. Pasteur. Juli 1903. - Jahresber. über die Leist. usw.

169. van der Scheer, Aphtae tropicae. Menses Bandb. der Tropenkrankh. 170. Wodder u. Duval, The Etiology of acute dysentery in the United States. Centralblatt für Balkteriologie. Bd. XXXI.

171. Veröffentlichungen des Kaiserl. Gesundheitsamtes. Jahrg. XXX. Nr. 28.

172. Virchow, Kriegstyphus und Ruhr. Virchows Archiv. Bd. LII.

173. Derselbe, Historisches, Kritisches u. Positives zar Lehre der Unterleibsaffelitionen. Ebenda. Bd. V.

174. Wittenberg, Ärztliche Erfahrungen in Südchina. Archiv f. Sch.- u. Tr.Hygiene. 1900. Nr. 1.

175. Wesener, Unsere gegenwärtigen Kenntnisse über Dysenterie in anatom. u. ätiolog. Hinsicht. Centralbl. f. allgem. Pathologie u. patholog. Anatomie. Bd. III.

176. Wolff $\mathrm{h}$ ü gel, Truppenhygienische Erfahrungen in China. Münchener med. Wochenschrift. 1903. Nr. 47-49.

177. Zorn, Beitrag zur Kenntnis der Amöbenenteritis. Deutsches Archiv f. klin. Medizin. Bd. LXXU. Nr. 14. 


\section{Erklärung der Abbildungen. \\ (Taf. I-VIII.) \\ Tafel I. \\ Amöbenruhr.}

Fig. 1. Außenseite des Anfangsstücks des Dickdarms mit (links) dem Blinddarm. Links oben der Wurmfortsatz. $P$ drohende Perforation. Die dunklen Stellen auf der Serosa entsprechen tiefen Geschwüren. Starke GefäBerweiterung im Peritonealüberzuge.

Fig. 2. Mucosa mit Muscularis mucosae. Dicht über letzterer ein kleines Amöbennest, in dessen nächster Umgebung das Gewebe vollkommen intakt ist, abgesehen von Lenkozytenansammlung. Weiter nach oben, hellgelb, Blutkörperchen. Darüber dicht gedrängte Amöben, welche die Epithelzellen einer Lieberkühnschen Drüse von anten nach oben zusammengeschoben und zum Teil von der Unterlage abgehoben haben. Eine Amöbe ist von unten her zwischen den Epithelzellen hindurch nach dem Lumen der Drüse zu vorgedrungen. Die Épithelien selbst sind in unmittelbarer Nachbarschaft der Amöben vollkommen erhaiten.

Eisen-Hämatoxylin-Färbung nach Weigert. Zeiss DD, Ocular 2, Tubuslänge 16. Zeichenapparat von Abbe.

\section{Tafel II.}

Amöbenruhr.

Ausgedehnter geschwüriger Zerfall der Schleimhant. Wallartig aufgeworfene Geschwürsränder. Die Schleimhant (grün) in Nekrosiernng begriffen.

\section{Tafel III}

A möbenruhr.

Fig. $3 a$. In mehreren lebenden Amöben rote Blntkörperchen. Ektoplasma und Endoplasma gut differenziert. Amöbenkerne nicht sichtbar. Rechts zwei weiße Blutkörperchen.

Fig. $3 b$ and $c$. Amöbenähnliche Zellen im Rahrstuhl. Kerne sehr deatlich hervortretend.

Wie aus dem Mabstabe der roten Blutkörperchen ersichtlich, sind die Zellen der unteren beiden Skizzen im Vergleich zu den Amöben der oberen etwas zu groß gezeichnet.)

\section{Tafel IV.}

Bazillenruhr.

Diphtheritische Verschorfung der Mucosa. Starke Rundzellenanhäufung. Kapillarektasien und Extravasate in der Submucosa (gelb).

Eisen-Hämatoxylin-Färbung nach Weigert. Zeiss AA, Ocular 2, Tubuslänge 16. Zeichenapparat von Abbe. 
48 Böse: Beobachtungen v. Erfahrungen Über Rutr in Ostasten.

Tafel $\nabla$.

Amöbenruhr.

Mehrere beginnende Geschwüre. Bei $a$ und $c$ ist die Schleimhaut bereits vollkommen zerfallen. Bei $b$ sind noch Reste ron ihr erhalten. Starke Verbreiterung der Submucosa.

Hämatoxylin-Eosin-Färbung. Zeiss $A_{2}$, Ocular 2, Tubuslänge 0. Zeichenapparat von $\mathrm{Abbe}$.

\section{Tafel VI.}

Chronische Amöbenruhr.

Fig. 1. Polypöse Entartang der Darmschleimhaut. Links ein Schleimpfropf von der Struktur der sogen. "Sagokörner“.

Hämatoxylin-Eosin - Färbung. Zeiss AA, Ocular 2, Tubaslänge 0. Zeichenapparat von Abbe.

Amöbenruhr.

Fig. 2. Stück aus der Submucosa. Die Amöben, ron denen einige bei $A$ sichtbar sind, dringen (auf der Abbildung von links unten nach rechts oben) in die Tiefe und lassen eine nekrotische Zone in Form der Flächen zweier gleichschenkliger Dreiecke, deren Basis nach der Mucosa zu, deren Spitze nach der Muscularis gewendet ist, hinter sich.

Färbung nach Giemsa. Zeiss AA, Ocular 2, Tubuslänge 16. Zeichenapparat von $\mathrm{Abbe}$.

Tafel VII.

Amöbenruhr.

Durchbruch der Gewebsnekrose von der Submucosa aus durch die Mucosa in dás Darmlumen. Die Mucosa ist in der Mitte bis auf einige eben noch sichtbare Reste von Drüsenschläuchen zerstört. Rechts und links zum gröBten Teil gut erhaltene Schläuche. Unter den Fundusepithelien der beiden am weitesten nach rechts gelegenen Drüsen Amöbennester. Das Epithel der einen Drüse ist durch die Amöben von unten her zusammengeschoben. Quer etwa durch die Mitte des Präparates zieht sich wallartig ein hyalines Netzwerk, welches Amöben einschließt. Mehr nach unten zu ist die Entstehung des Netzwerkes sichtbar. Die Maschen sind hier noch hellrot gefärbt.

Eisen-Hämatoxylin-Färbung nach Weigert. Zeiss AA, Ocular 2, Tubuslänge 0. Zeichenapparat von Abbe.

\section{Tafel VIII.}

Amöbenruhr.

Massenhafte Amöbenansammlung in der Nähe einer Submucosavene. In lẹtzterer Blat und einige Amöben.

Färbung mit Giemsalösung. Zeiss DD, Ocular 2, Tubuslänge 16. Zeichenapparat von $\mathrm{Abbe}$. 


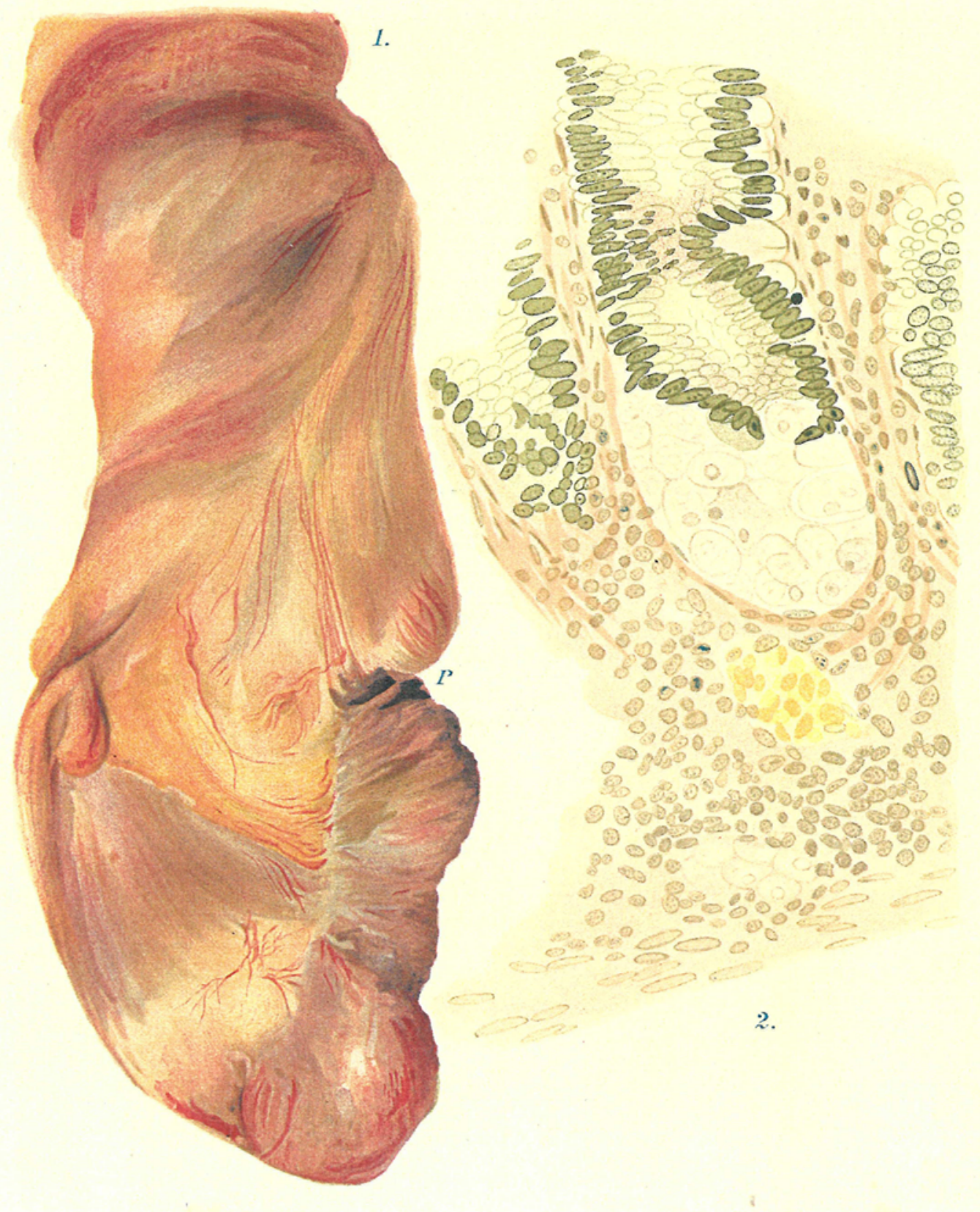




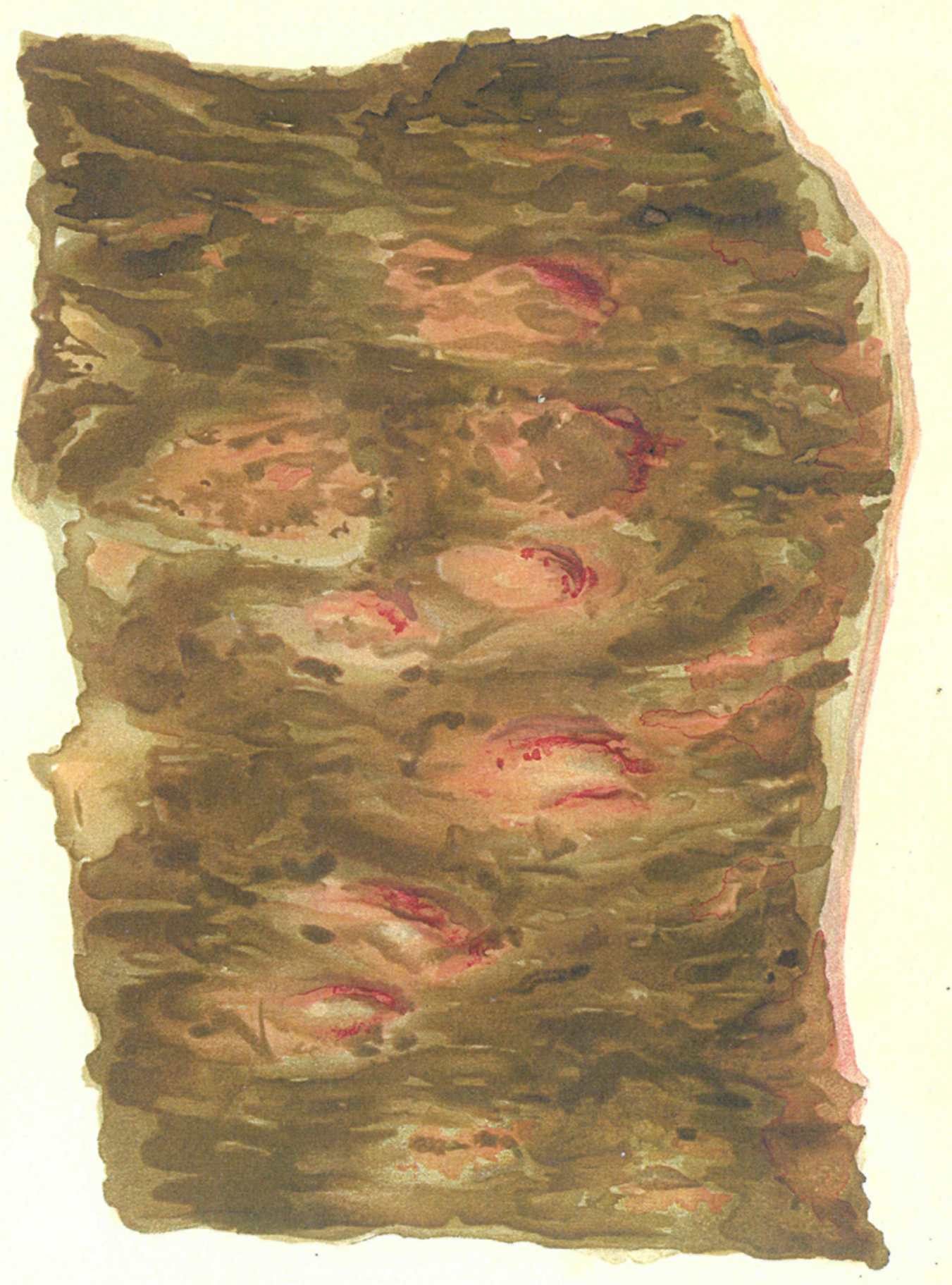

Verlag Veit \&Comp. Leinzio.

Lith. Anst vE. A Furie, Leigrig. 


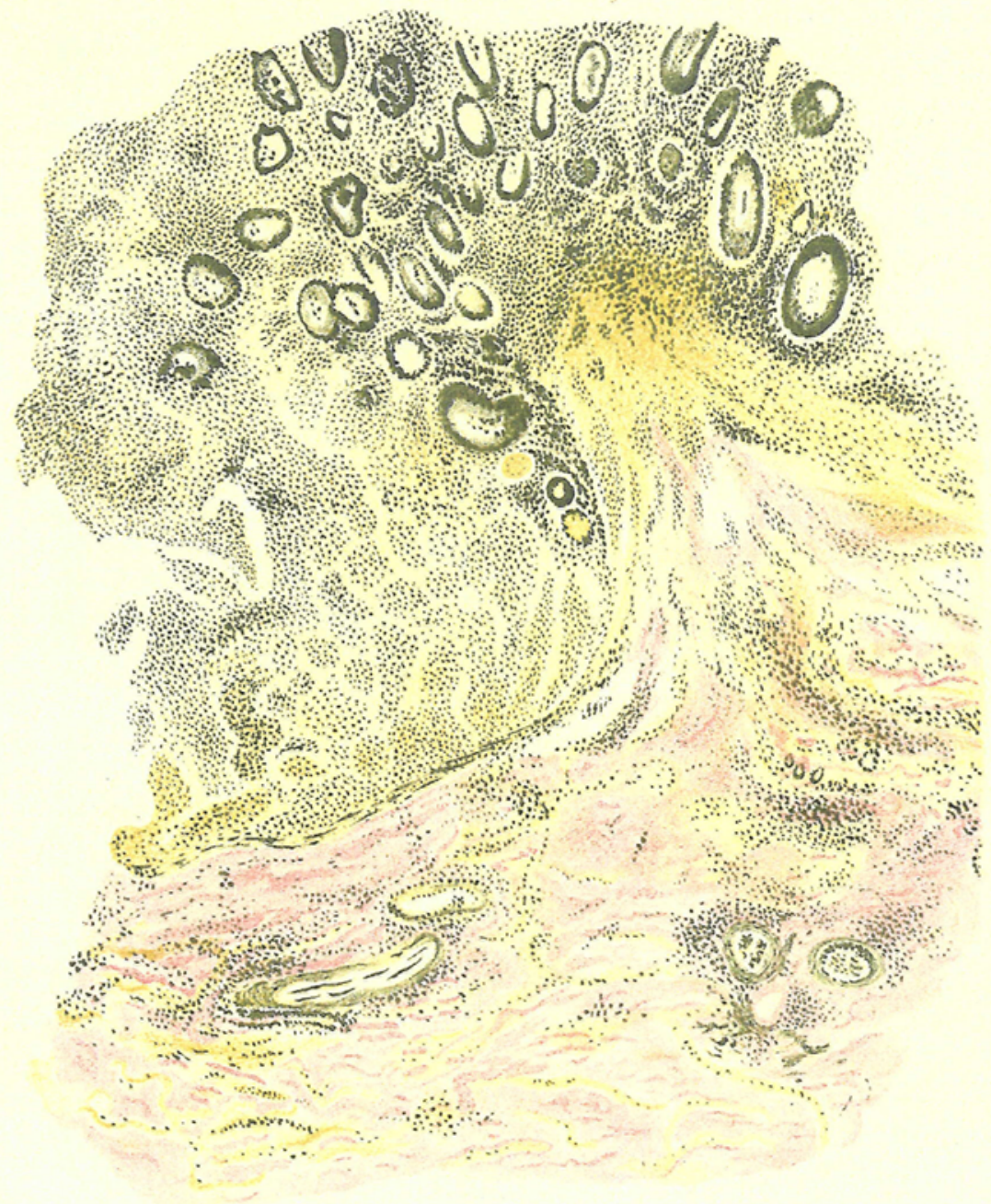


Zeitschrift für Hygiene. Bd. LXI.

Tafel $V$.

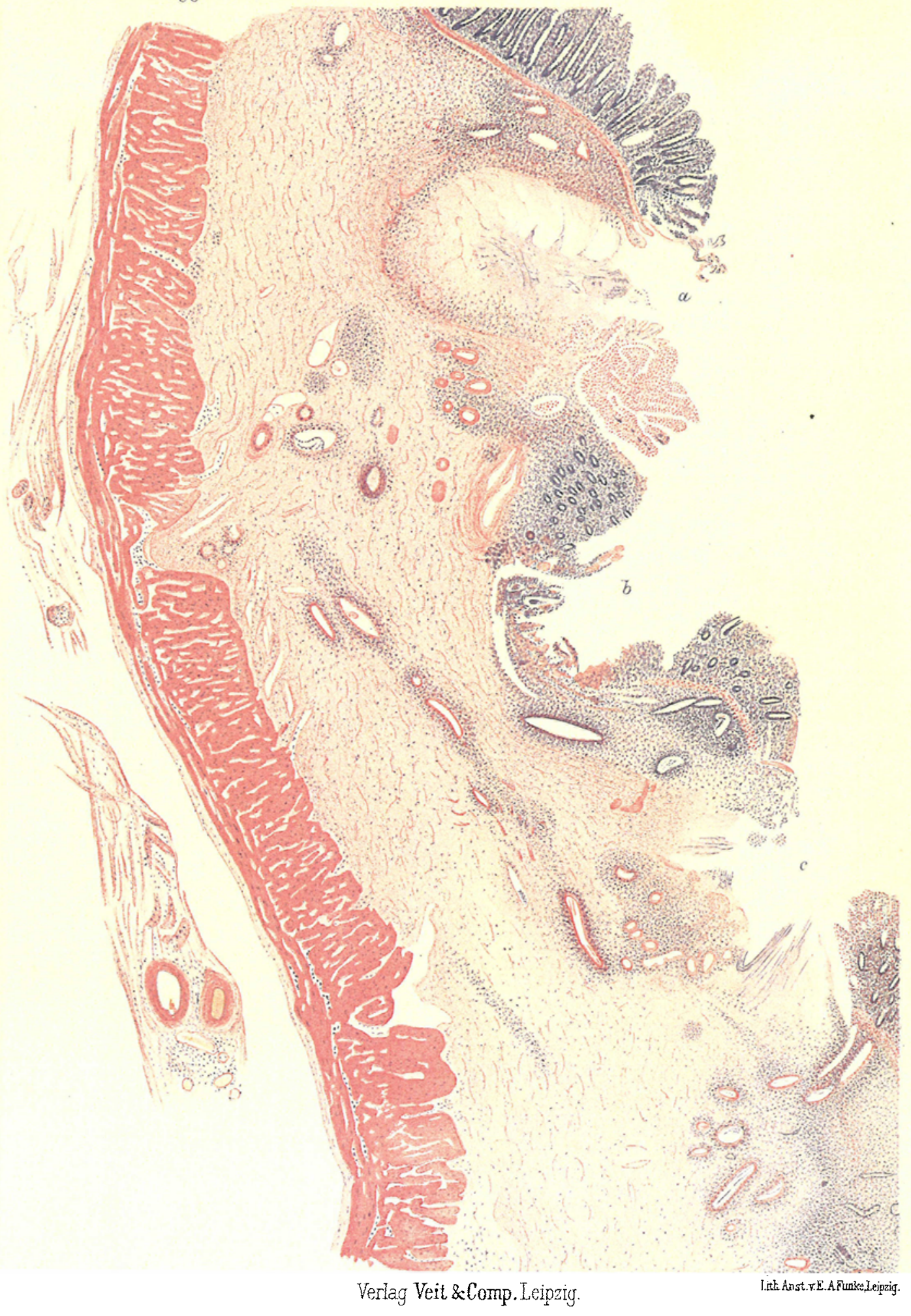




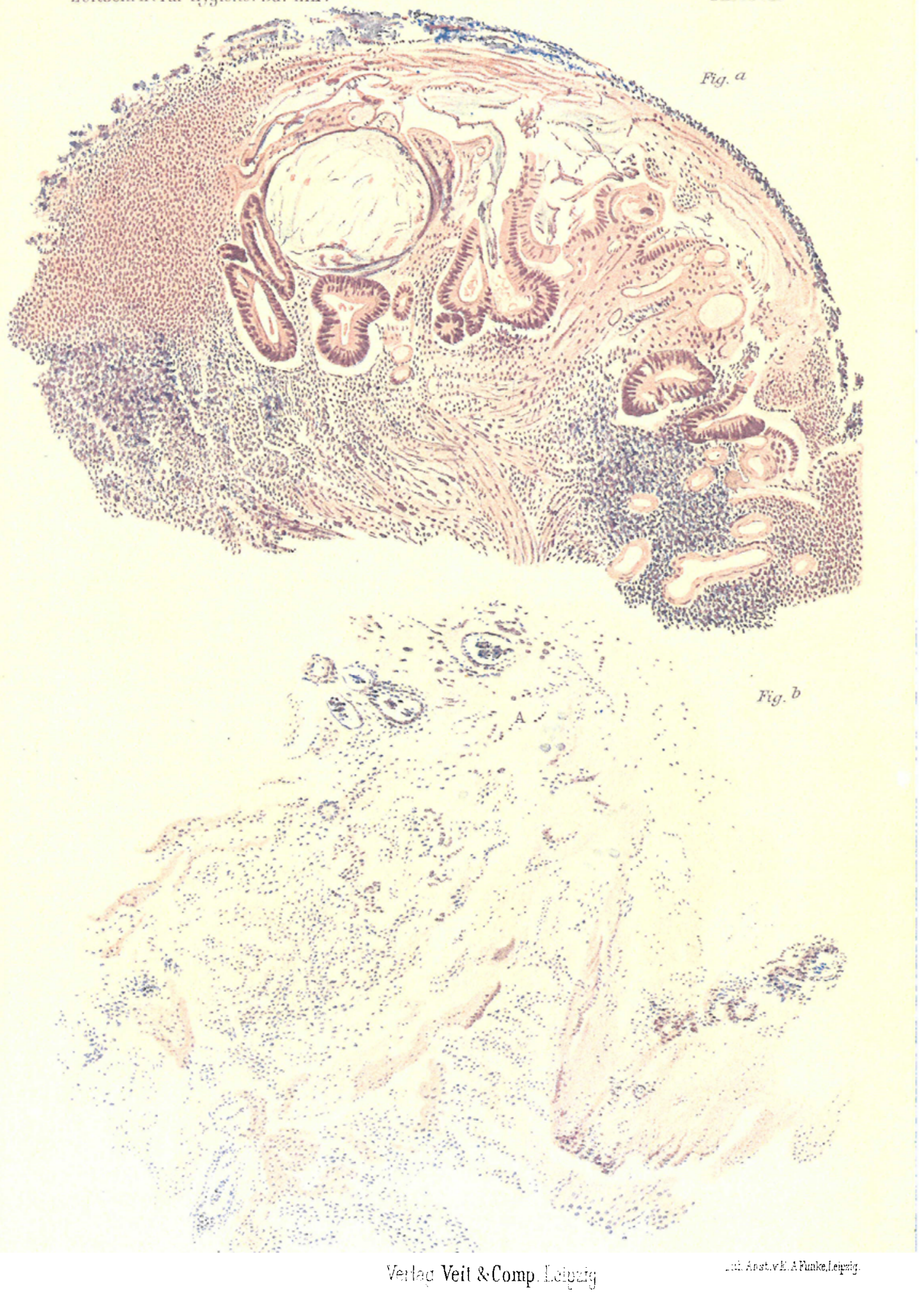




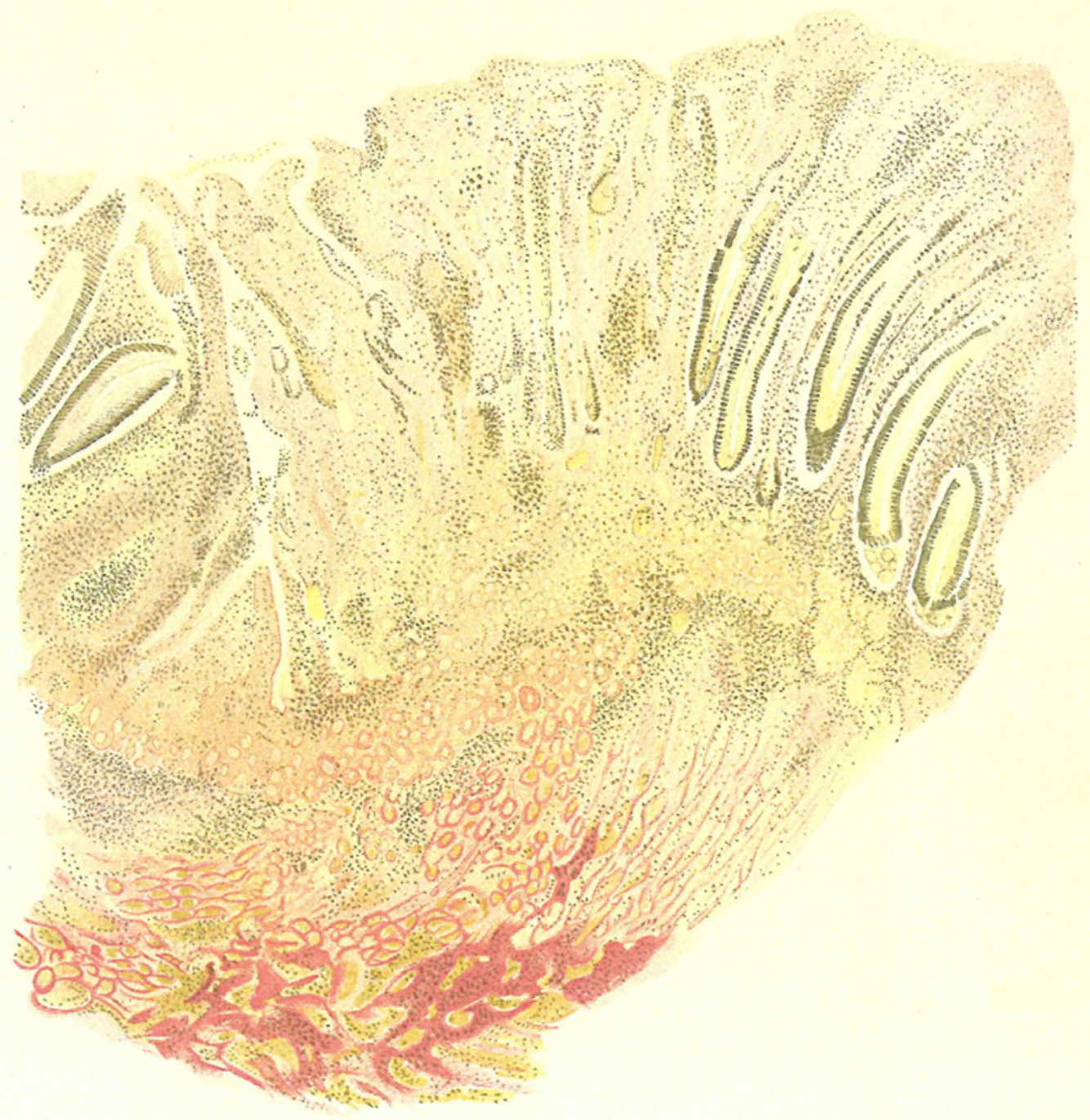




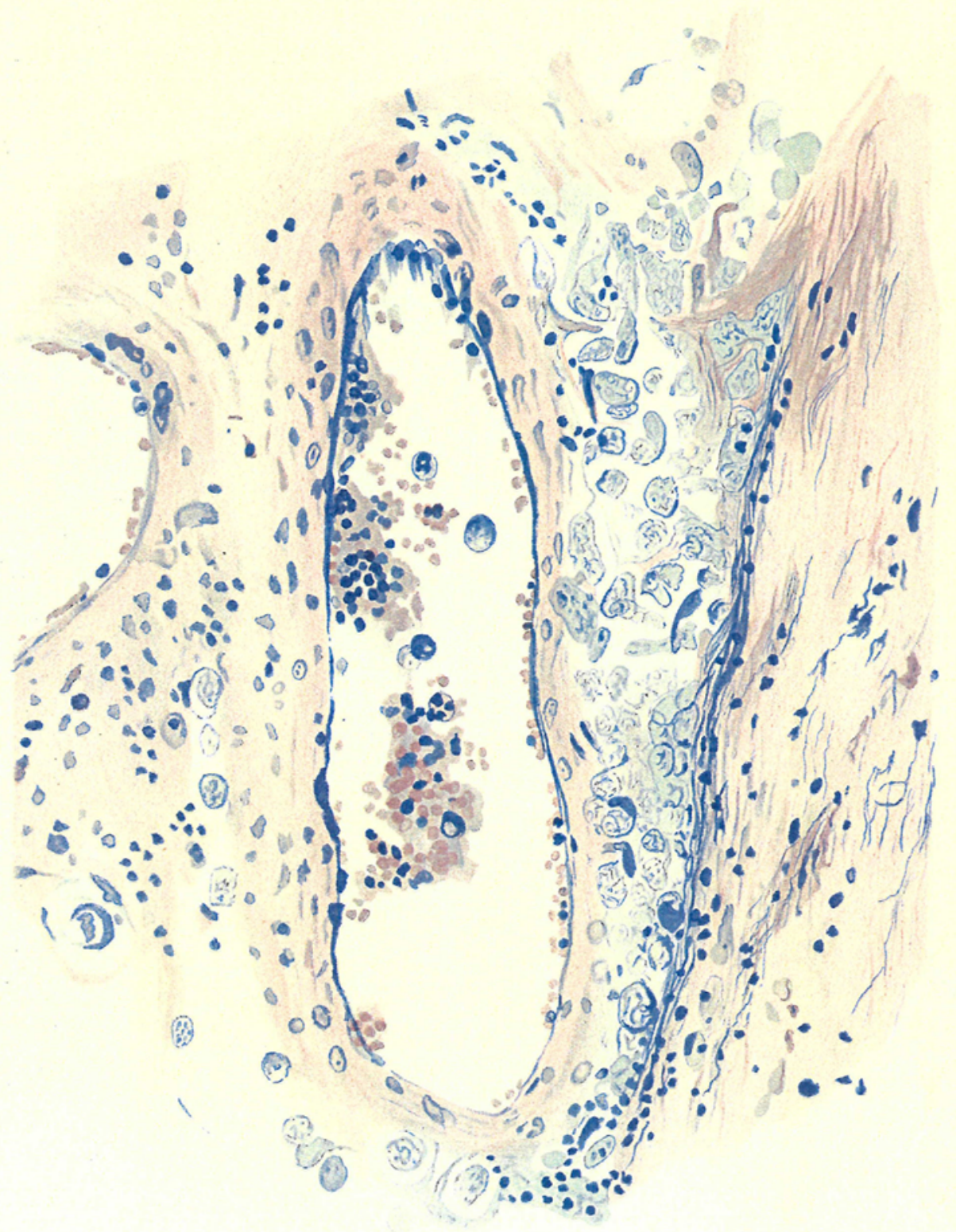

